\title{
Elaborate Modeling and Fragility Assessment of a Multiframe PC Box-Girder Bridge with Intermediate Hinges in California
}

\author{
Tong Wu, ${ }^{1,2}$ Zhan $\mathrm{Li}^{3}$ and Shengchun Liu $\mathbb{D}^{1}$ \\ ${ }^{1}$ School of Electronic Engineering, Heilongjiang University, Harbin 150080, China \\ ${ }^{2}$ School of Civil Engineering, Heilongjiang University, Harbin 150080, China \\ ${ }^{3}$ China Institute of Marine Technology \& Economy, Beijing 100081, China \\ Correspondence should be addressed to Shengchun Liu; liushengchun@hlju.edu.cn
}

Received 23 July 2021; Accepted 7 September 2021; Published 8 October 2021

Academic Editor: Shan Gao

Copyright $\odot 2021$ Tong Wu et al. This is an open access article distributed under the Creative Commons Attribution License, which permits unrestricted use, distribution, and reproduction in any medium, provided the original work is properly cited.

Multiframe PC box-girder bridge with intermediate hinges is a kind of bridge having complex structural characters, which is very quintessential in California. In this study, a typical bridge was adopted to establish a nonlinear dynamic model through OpenSees platform. Intermediate hinge and inhibiting devices in it were elaborately simulated. Meanwhile, pushover analysis was used to reinstate a specimen of column test, which has the similar ratio of reinforcement to the typical bridge, and the hysteretic model parameters of the longitudinal steels inside columns were obtained. The damage indexes of column and hinge, which are primary components, under different limit states were acquired by moment-curvature analysis. Taking into account the uncertainty, nonlinear time-history analysis of the bridge was carried out through a suite of synthetic ground motions. Subsequently, a probabilistic seismic demand model was developed, and fragility curves were further focused on. According to fragility assessment, the conclusion shows that columns and hinge restrainers exhibit high fragility, and bridge system fragility is gradually determined by column fragility along with aggravating of the damage state. Unseating of girder can hardly occur at abutments and intermediate hinges. Moderate limit state could be exceeded in the positions of plug-type concrete structures in intermediate hinges, which tends to create transverse and vertical cracks, furthermore causing reinforcements yield. It indicates that it would severely underestimate the seismic fragility of intermediate hinges without considering the elaborate simulation of hinges.

\section{Introduction}

California, where the prestressed concrete viaducts were generally designed to the form of column-girder consolidation, is located in the San Andreas fault [1,2], which is the part of the Circum-Pacific seismic belt. In order to release the freedom of bridges and reduce the number of cracks, the intermediate hinges $[3,4]$ were designed in some spans of bridges [5], shown in Figure 1. Hinges are generally located next to $1 / 6 \sim 1 / 4$ point of span length, which were designed to the form of upper-lower and left-right occlusion, called plug-type, shown in Figure 2. Moreover, inhibiting devices were designed inside hinges to limit displacement, including longitudinal restrainers, vertical elastomeric bearings, and transverse elastomeric pads. This type of bridge, called multiframe prestressed concrete box-girder bridge, has been widely used in California and even throughout the United States, due to its perfect integrity and large spanning ability.

In the process of vibration, the bending moment of the bridge decreases to zero at the point of hinges. Hinge, taken as the boundary, makes the column-girder consolidation on both sides of it present the vibration characteristic, which is the similar to frame. The overall vibration form of the bridge can be outlined as follows: the individual vibration of each frame is connected into the overall vibration of the bridge by hinges. Consequently, the vibration characteristic and vibration rule of hinge, as a key component of connecting every single frame, are particularly crucial. Several studies [6-8] have stated that the linear elastic model was often used to simulate the elements of girder due to rare occurrence of plastic failure here. In addition, in order to simplify finite element calculation, relative displacement at the point of 


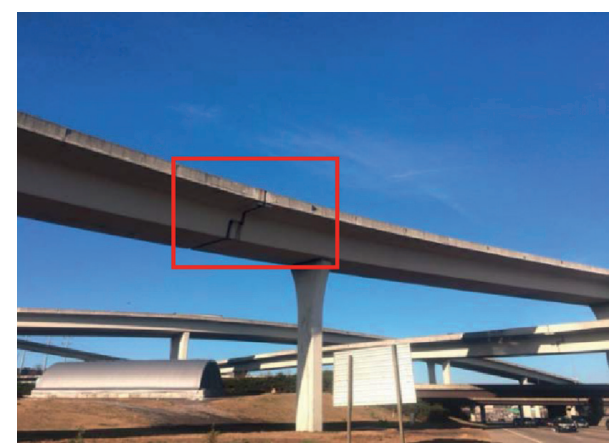

Figure 1: Intermediate hinge.

hinge was neglected in vertical and transverse directions $[7,8]$. Thus, the hinge points belonging to adjacent frames were imitated to be fixed in vertical and transverse directions, and only tensile and compressive action of longitudinal restrainers between adjacent frames was considered $[9,10]$. The previously mentioned simplification tended to ignore the potential damage at the point of hinge, which may have a considerable impact on fragility analysis and risk assessment of the bridges.

Meanwhile, the provided concrete uniaxial material and steel uniaxial material, such as Concrete07 and reinforcing steel in OpenSees [11], are often combined to simulate the columns. This combination does not take into account the diversity of column sections, which will undoubtedly reduce the accuracy of the hysteretic performance of the columns and increase the error. Because of the important influence of columns on the overall dynamic characteristics of the bridge [12-15], the column experiment, which matches with the actual columns, should be used to obtain the material constitutive relationship of the columns, so that the obtained column hysteresis model will be more reliable.

The previously mentioned findings collectively demonstrate that the multiframe prestressed concrete box-girder bridge has complex characteristics combined with consolidation of girder and column and frame structure. For the bridge with large spans, high columns, and multihinges, especially, its structural complexity should be very prominent. Consequently, it is indispensable to assess the seismic fragility of this type of bridge in depth. In spite of quite a few relevant researches being done, the unsolved question, particularly regarding the refined intermediate hinge modeling, still needs to be solved. If this question is neglected, some damage positions may be missed, and the potential hidden danger may be caused.

The fragility analysis is a method of risk assessment for structures $[16,17]$, which combines two kinds of uncertainties, the ground motion intensity uncertainty and structural parameters uncertainty, organically by probability and statistics algorithm [18]. Damage indexes to limit states are obtained by the experimental and empirical statistical results, while seismic demands of structures are obtained through time-history analysis, and further probabilistic seismic demand models are established. The fragility analysis, used for predisaster prevention and postdisaster loss assessment, has become the most efficient and effective approach to risk assessment of structures and is adopted extensively in the field of disaster prevention and mitigation $[19,20]$.

Considering the limitation of previous works, this study focuses on a multiframe prestressed concrete box-girder bridge with eight spans and double intermediate hinges. Elaborate nonlinear analytical models of this bridge, serving as a template of simulation to the similar type of bridge, which accounts for the nonlinear behavior of girders, plug-type hinges, columns, bearings, and abutments, are developed in the OpenSees platform. The damage indexes of bridge components are selected scrupulously through data screening and Xtract analysis. Subsequently, fragility curves of bridge components and bridge system are developed, while seismic damage exceedance probabilities are acquired. The study can provide data reference and theoretical basis for seismic damage assessment and preearthquake protection of the same type of bridges.

\section{Numerical Modeling of the Bridge}

2.1. Characteristics. A typical bridge (Figure 2(a)), designed in 1991, built in 1993, and located in California, US, is a prestressed concrete curved box-girder bridge with eight spans (Table 1). The superstructure for this prestressed concrete box-girder curved bridge has a degree of curvature $34^{\circ}(0.593 \mathrm{rad})$ and a centerline radius of $914.4 \mathrm{~m}$. Between the midspan of \#2 span and the midspan of \#7 span, the depth of deck section changes from $2.59 \mathrm{~m}$ at the midspan to $3.81 \mathrm{~m}$ at the supported point through parabola, and the depth of section for any other parts of superstructure is $2.59 \mathrm{~m}$. Figure 2(b) shows the cross section of the two-lane box girder rigidly connected by bridge columns. All the columns have different heights with a range from $8.53 \mathrm{~m}$ to $42.67 \mathrm{~m}$ (Table 2 ), each connected to a single pile foundation. On each abutment (Figure 2(c)), two elastomeric pads with the size of $914 \mathrm{~mm} \times 610 \mathrm{~mm} \times 51 \mathrm{~mm}$ are used to support the vertical loads while allowing horizontal translation through a frictional surface. Also, two shear keys near the elastomeric pads in each abutment are placed to restrain the transverse translation of the superstructure. Each abutment is supported by a rectangular footing. Figures $2(\mathrm{~d})-2(\mathrm{f})$ show the plan, cross section, and elevation of the intermediate hinges, located in the \#3 and \#6 spans, which divide the bridge into three frames (Figure 2(a)). Two horizontal elastomeric bearings (Figure 2(e)) are installed to sustain vertical compression and restrain horizontal shear deformation (i.e., the relative horizontal displacement between the adjacent decks in the intermediate hinge). Besides, four transverse compressive pads (Figure 2(e)) are designed to sustain transverse compression and restrain vertical shear deformation (i.e., the relative vertical displacement between the adjacent decks in the intermediate hinge). Figure 2(f) shows that the girder deck ends in the intermediate hinge and is connected by longitudinal restrainers. Polystyrene is stuffed into the gap in the intermediate hinge (Figures $2(\mathrm{~d})$ and $2(\mathrm{f}))$.

2.2. Numerical Simulation. In this study, OpenSees program [21] was employed to simulate the typical bridge. A threedimensional numerical model of the typical bridge, the 


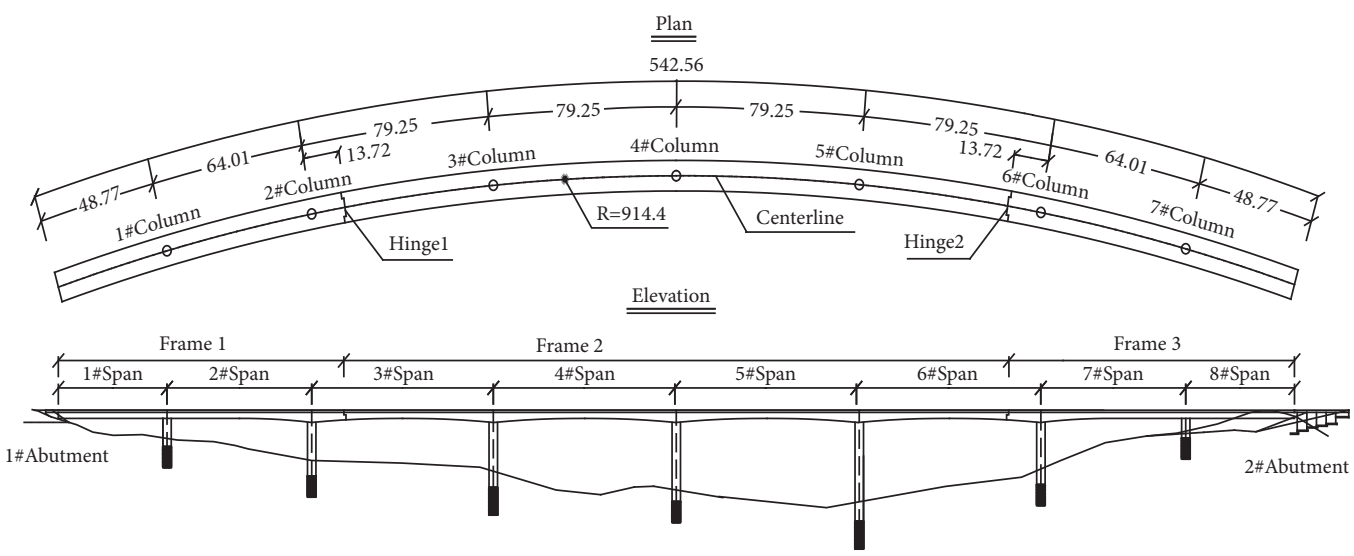

(a)

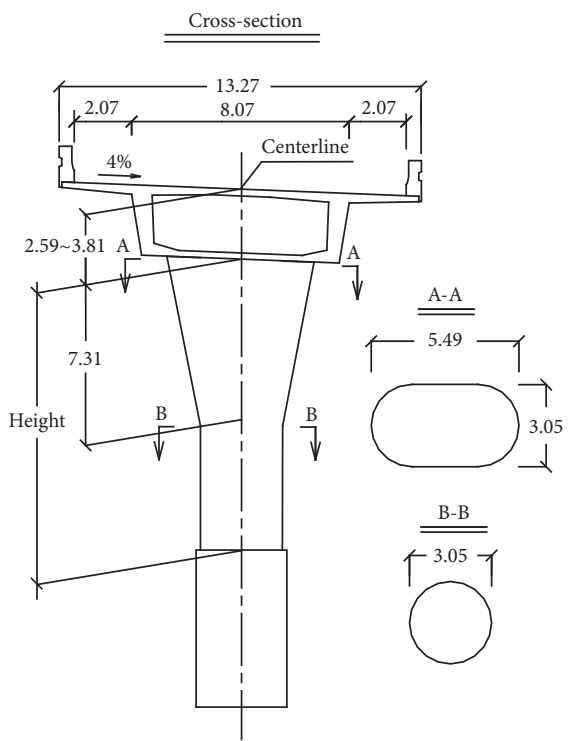

(b)

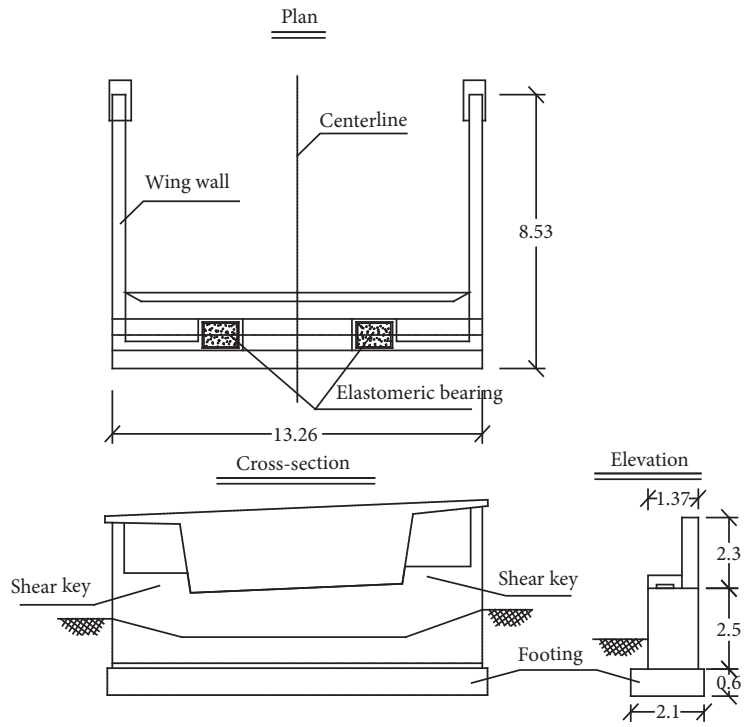

(c)

Figure 2: Continued. 


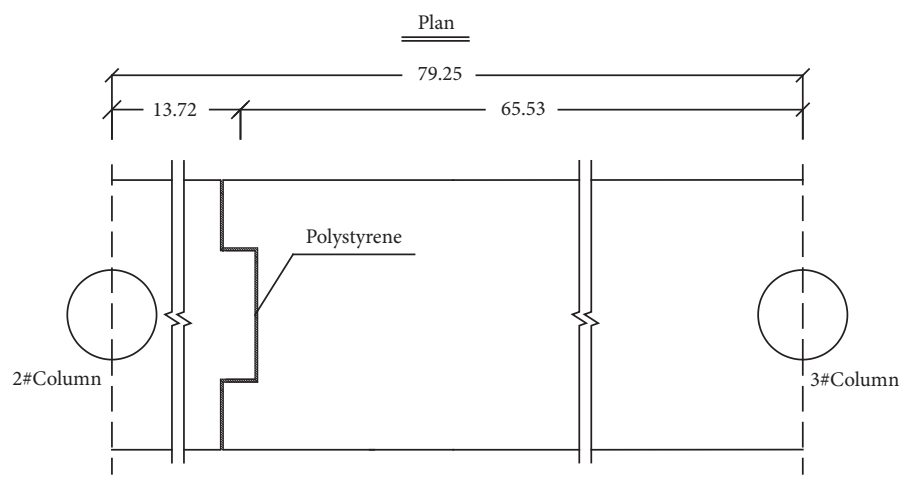

(d)

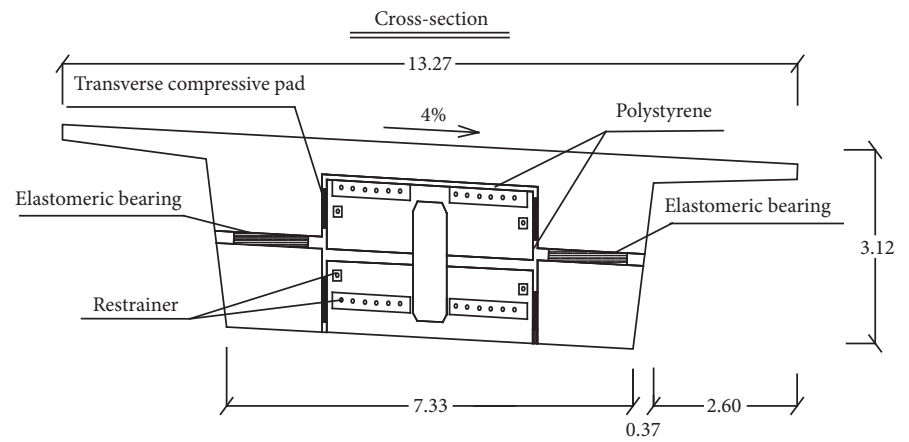

(e)

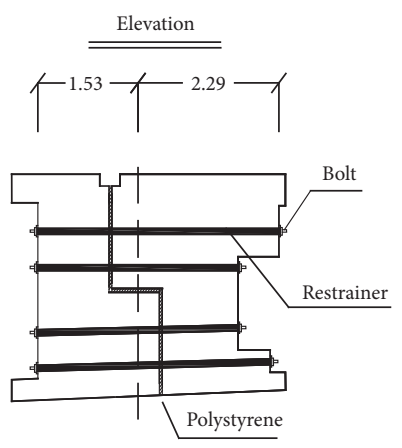

(f)

Figure 2: Schematic view of the typical bridge (m). (a) Bridge plan and elevation. (b) Girder and column cross section. (c) Abutment plan, elevation, and cross section. (d) Hinge span plan. (e) Hinge cross section. (f) Hinge elevation.

constitutive relation of the materials, and the force-displacement relation of the component models are shown in Figure 3. In order to acquire the response of intermediate hinge under seismic load, the girder elements were set as a displacement-based beam-column element considering elastic and plastic properties. So girders, hinges, columns and prestressing tendons were all modeled by the elasticplastic element, which is different from previous studies [6-10].

A concrete model, Concrete07, developed by Chang and Mander [22, 23], was used to simulate the confined and unconfined concrete in girders, hinges, and columns, illustrated in Figure 3(b).

The column is the most important component that affects the overall seismic performance of the bridge. In order to improve the accuracy of the column simulation, the longitudinal steels of columns were modeled through hysteretic material in OpenSees, while the concrete was modeled by Concrete 07 . The hysteretic material parameters were determined by the following process. An experiment of column, Lehman 415S [24], with the similar reinforcement ratio to the typical bridge columns, was simulated by OpenSees. The hysteretic process of the experimental column was obtained through pushover analysis. Obviously, different hysteretic parameters of the longitudinal steels corresponded to different hysteretic results. Through a large amount of pushover analysis and trials to column models with different hysteretic parameters, the hysteretic process of a simulative column, which was most matching with the hysteretic process of the experimental column, was screened out. The hysteretic process of the simulative column and the backbone curves between the simulative and the 
TABle 1: Span length (m).

\begin{tabular}{lccccccccc}
\hline Spans & $1 \#$ & $2 \#$ & $3 \#$ & $4 \#$ & $5 \#$ & $6 \#$ & $7 \#$ & 8\# & Total \\
\hline Length $(\mathrm{m})$ & 48.77 & 64.01 & 79.25 & 79.25 & 79.25 & 79.25 & 64.01 & 48.77 & 542.56 \\
\hline
\end{tabular}

TABle 2: Column height (m).

\begin{tabular}{lccccccc}
\hline Columns & $1 \#$ & $2 \#$ & $3 \#$ & $4 \#$ & $5 \#$ & $6 \#$ & $7 \#$ \\
\hline Height $(\mathrm{m})$ & 12.19 & 23.16 & 28.04 & 34.14 & 42.67 & 26.82 & 8.53 \\
\hline
\end{tabular}

experimental columns are shown in Figures 4(a) and 4(b), respectively. The hysteretic parameters of the longitudinal steel model of the most matching simulative column are presented in Table 3. The model of longitudinal steels in columns is illustrated in Figure 3(c).

A uniaxial Giuffre-Menegotto-Pinto steel material object [25] with isotropic strain hardening, which can simulate the initial tensile stress, was used to model the prestressing tendons through Steel02 material in OpenSees. \$sigInit was used to load the initial stress value of tendons. The prestressing tendon elements were connected to the girder elements through rigid links.

The model developed by Muthukumar [26] was used to represent the shearing force and displacement of elastomeric bearings located at abutments and hinges. Steel01 material was chosen to establish the bilinear relationship of bearing zero-length elements, illustrated in Figure 3(d).

In consideration of the supporting reaction in hinges, the vertical compressive state of the elastomeric bearings in hinges was simulated. The relationship of compressive force and displacement of elastomeric bearings in hinges was captured through the experimental report, "Nonlinear Finite Element Analysis of Elastomers" [27]. The compressive stress-strain relationship of the experimental rubber bearing is listed in Figure 5 [27]. The compressive force and displacement relationship of simulative bearing is listed in Figure 3(e), where initial stiffness and compressive yield stiffness was modeled by elastic material and ElasticPPGap material, respectively. Meanwhile, the parallel material made two previously constructed materials together.

The bilinear model derived from Hertz model considering hysteretic damping, referring to the study of Muthukumar [26] and DesRoches et al. [28], was used to simulate the pounding performance between abutment and girder, as well as hinge and girder, illustrated in Figure 3(f). The bilinear model was modeled using ElasticPPGap material in OpenSees platform, and pounding stiffness parameters were suggested from Nielson's study [29], where $K_{t 1}=586.3(\mathrm{kN} / \mathrm{mm}) / \mathrm{m}, \quad K_{t 2}=201.73 \quad(\mathrm{kN} / \mathrm{mm}) / \mathrm{m}$, $K_{\text {eff }}=238.5(\mathrm{kN} / \mathrm{mm}) / \mathrm{m}, \Delta_{y}=2.54 \mathrm{~mm}$, and $\Delta_{m}=25.4 \mathrm{~mm}$.

Abutment components, including passive performance, footing transverse response, bearings, and shear keys, were simulated in detail below.

The force vs. displacement response of the abutment backfill was simulated by HyperbolicGap material in OpenSees, which was proposed by Shamsabadi et al. [30, 31]. The nonlinear relationship between the passive force and the abutment displacement was tested by using an abutment model with a backwall height of $1.68 \mathrm{~m}$. The curve between the passive force and displacement is shown in Figure 3(g), where, $F_{\text {ult }}$ represents the passive force corresponding to the maximum passive displacement $\Delta_{\max }, \Delta_{\text {ave }}$ represents passive displacement corresponding to $1 / 2$ of $F_{\mathrm{ult}}$, and $K_{\mathrm{Ini}}$ represents mean stiffness of soil.

The transverse force vs. displacement response of the footings beneath the abutments was modeled through soil springs using hysteretic material in OpenSees, shown in Figure 3(h), where the yield stiffness and yield displacement were calculated based on the study of Gazetas and Tassoulas [32], as well as Gadre and Dobry [33].

The shear keys play an important role in resisting the transverse seismic load and limiting the transverse displacement of the bridge. In the event of an earthquake, the shear keys transfer the inertial force of the superstructure to the abutments and the bent caps; sequentially, the abutments and the bent caps transfer the force to the foundations. If the response of the superstructure exceeds the shearing strength of the shear keys, the transferring function of the shear keys can be instantly lost. The ElasticPPGap material in OpenSees was used to simulate the force vs. displacement relationship of shear keys in abutments, illustrated in Figure 3(i), which was based on a strut-and-tie analogous model proposed by Megally et al. [34, 35].

The hinges are located in the \#3 and \#6 spans of the bridge, which is about 1/6 span length away from the supporting point. The form of hinge is upper-lower and leftright occlusion, called plug-type. The inhibiting devices, set in the hinges, are used to limit the potential moving displacement, and the gap between hinge and girder is filled with polystyrene. Longitudinally, restrainers, composed of 28 high strength steel bundles with the diameter of $3.175 \mathrm{~cm}$, anchored on the concrete on both sides of the hinges. The restrainers, bearing longitudinal tension, and compression are used to connect the left and right frames, limit the longitudinal relative displacement, and restrain the longitudinal collision. Transversely, four transverse compressive pads, with the size of $838.2 \mathrm{~mm} \times 381 \mathrm{~mm} \times 76.2 \mathrm{~mm}$, are used to alleviate the lateral relative displacement in order to restrain the lateral collision, as well as providing vertical shear strength to inhibit the vertical relative displacement. Vertically, two elastomeric rubber bearings, with the size of $1447.8 \mathrm{~mm} \times 609.6 \mathrm{~mm} \times 177.8 \mathrm{~mm}$, are used to bear the compression of the vertical supporting reaction, resist the transverse shear deformation, and restrain the lateral collision.

Previous studies [6-10] believed that the overlimited curvature of concrete cannot occur in hinges, so the hinges were simulated to linear elastic elements. Meanwhile, most of the inhibiting devices in hinges were ignored through connecting the elements rigidly in transverse and vertical direction, except for the longitudinal restrainer being 


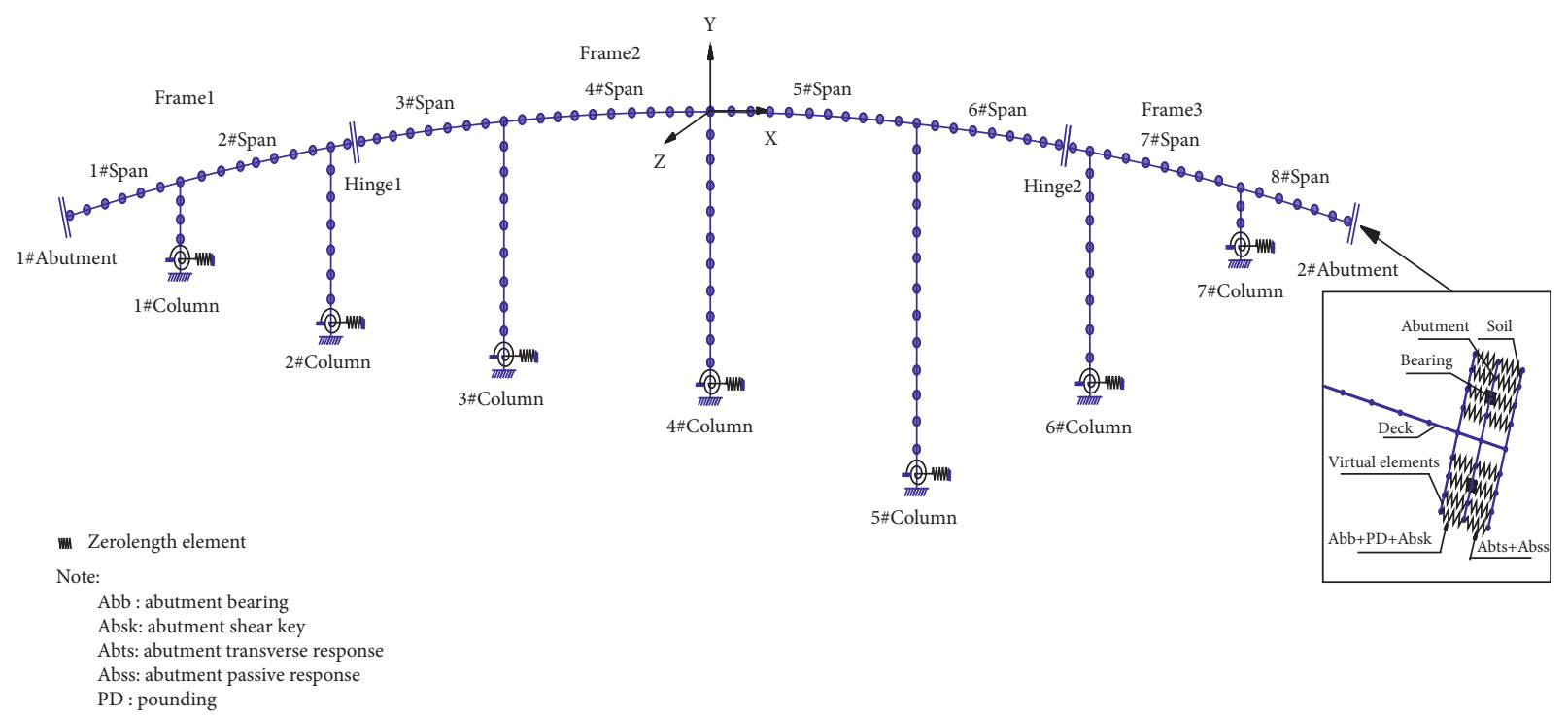

(a)

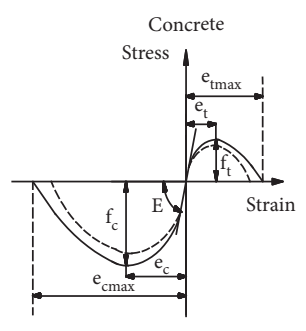

Column steel
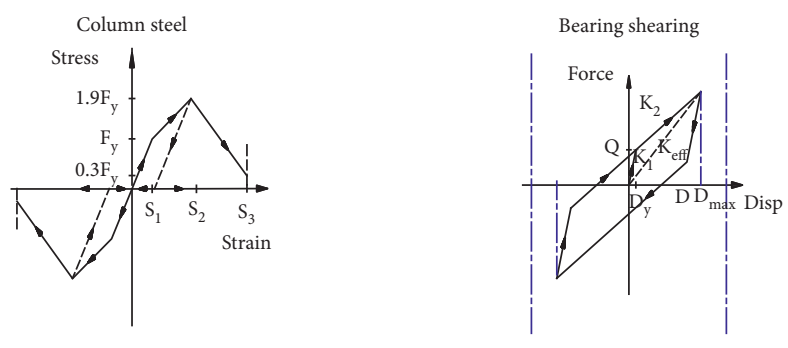

- Confined Concrete

- - - Unconfined Concrete

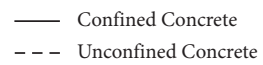

(c)

(b)

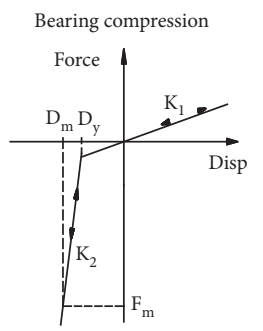

- Confined Concrete

- - - Unconfined Concrete

(e)

Abutment transverse response

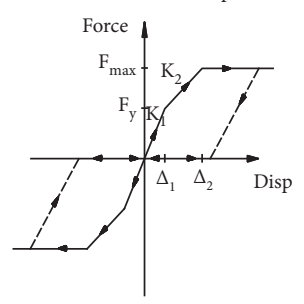

_ Confined Concrete

- - - Unconfined Concrete

(h)
Pounding element

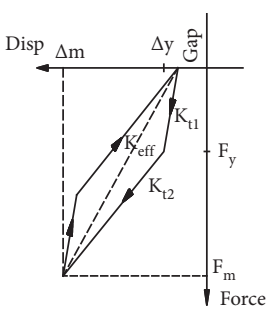

_ Confined Concrete

- - - Unconfined Concrete

(f)

Abutment shear key

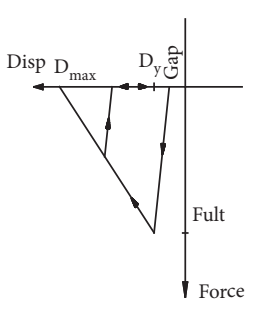

Confined Concrete

- - - Unconfined Concrete

(i)

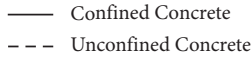

(d)

Abutment passive response

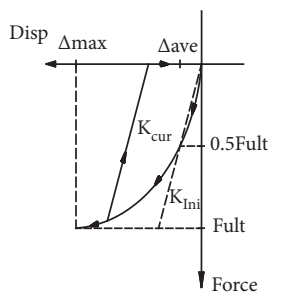

- Confined Concrete

- - - Unconfined Concrete

(g)

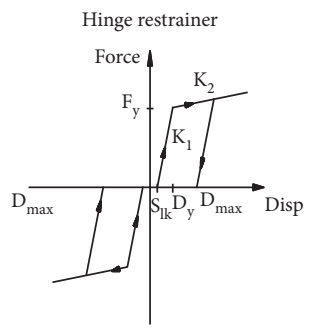

- Confined Concrete

- - - Unconfined Concrete

(j)

Figure 3: Schematic representation and global coordinate of the numerical model. (a) Bridge. (b) Concrete. (c) Longitudinal steel in column. (d) Bearing (shearing). (e) Bearing (compression). (f) Pounding. (g) Abutment passive performance. (h) Abutment transverse response. (i) Shear key. (j) Hinge restrainer. 


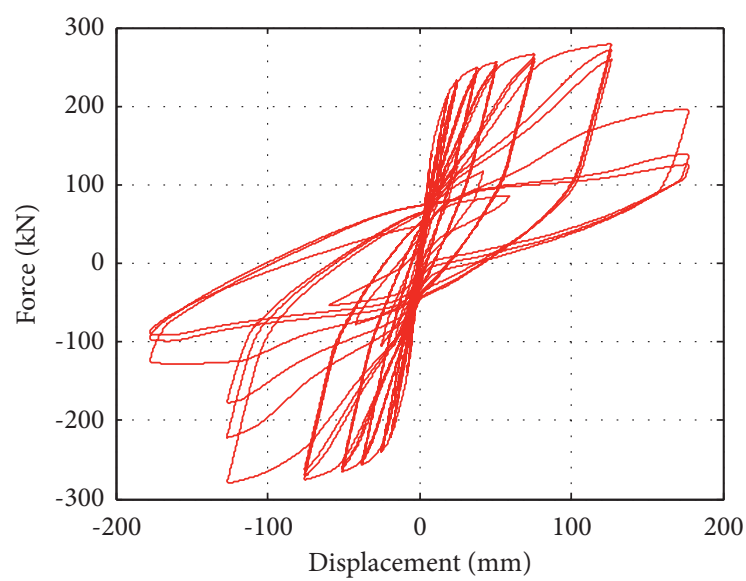

(a)

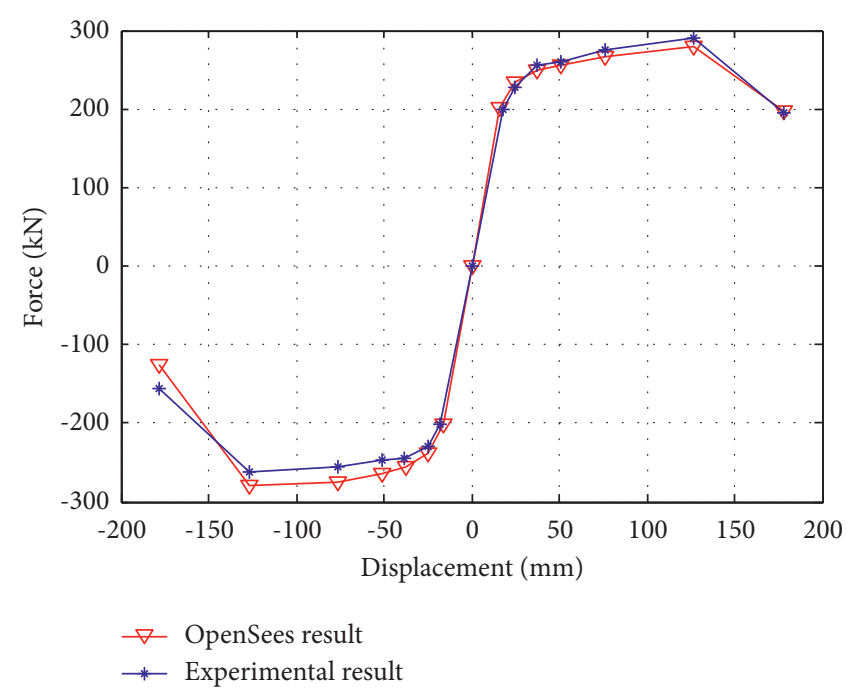

(b)

FiguRE 4: Hysteretic process of column. (a) Hysteresis curve of the simulative column. (b) Comparison of backbones between simulation and experiment.

TABle 3: Parameters of hysteretic material for longitudinal steels in columns.

\begin{tabular}{lcc}
\hline Number & Parameters & Values \\
\hline 1 & $\$ \mathrm{~s} 1 \mathrm{p}$ & $\$$ fys \\
2 & $\$ \mathrm{e} 1 \mathrm{p}$ & 0.003 \\
3 & $\$ \mathrm{~s} 2 \mathrm{p}$ & $1.9 * \$$ fys \\
4 & $\$ \mathrm{e} \mathrm{p}$ & 0.13 \\
5 & $\$ \mathrm{~s} 3 \mathrm{p}$ & $0.3 * \$$ fys \\
6 & $\$ \mathrm{e} 3 \mathrm{p}$ & 0.28 \\
7 & $\$ \mathrm{~s} 1 \mathrm{n}$ & $-\$$ fys \\
8 & \$e1n & -0.003 \\
9 & \$s2n & $-1.9 * \$$ fys \\
10 & \$e2n & -0.13 \\
11 & \$s3n & $-0.3 * \$$ fys \\
12 & \$e3n & -0.28 \\
13 & \$Pinchx & 0.7 \\
14 & \$Pinchy & 0.85 \\
15 & \$damage1 & 0.00 \\
16 & \$damage2 & 0.33 \\
17 & \$beta & 0.05 \\
\hline
\end{tabular}

${ }^{1}$ \$fys represents the yield strength of steel.

simulated. The previously mentioned simulation can miss the possibility of bending failure of occlusion concrete in hinges. However, in the event of earthquake, the huge inertial load, aggravating the reaction force of the supporting point, results in great bending moment at the root of occlusion concrete in hinge, which can cause the risk of overlimited curvature [36].

In view of the previously mentioned analysis, the hinges were simulated elaborately, shown in Figure 6, using displacement-based beam-column element. The slave elements, generated from the slave nodes, were established to reproduce the precise positions of the occlusion concrete of the hinges. In order to integrate the slave nodes with the master nodes in hinges, Rigidlink constraint was used to connect two kinds of nodes. Zero-length elements were used to simulate inhibiting devices, such as elastomeric bearings, transverse compressive pads, longitudinal restrainers, and pounding elements in the hinges, as shown in Figure 6.

In the simulation of restrainers, the high strength steel bundles, which are closely bonded to concrete in most length range, are considered having an initial slack in the cables. Once deformation exceeds the slack, the restrainers bear the tension and compression load. According to the study of Ramanathan [37], the initial slack conformed to a uniform distribution bounded between $6.35 \mathrm{~mm}$ and $25.4 \mathrm{~mm}$. Meanwhile, the length and the material strength of high strength steel bundle were both considered in simulation, illustrated in Figure 3(j). UniaxialMaterials of ElasticPPGap and Parallel were used simultaneously to capture the force deformation response of restrainer cables.

The pile foundations were simulated through lumped translational and rotational springs at the bases of the columns, calculated by LPILE2018 [38].

2.3. Modeling Uncertainties. During the process of design, the designed parameter of bridge was adopted in a certainty form, but during the process of construction and serving, some parameters, like strength, stiffness, geometry, damp, mass, and so on, showed uncertainty within a range $[39,40]$. This kind of uncertainty, called cognitive uncertainty, is implemented through imitating the uncertainty of parameter in finite element model when performing the probabilistic seismic demand analysis. Multidimensional stratified sampling method, Latin hypercube sampling (LHS), was adopted to sample the uncertain parameters. The LHS sample data of 10 selected uncertain parameters, including the strength of concrete, yield strength of reinforcement, shear modulus of elastomeric pad, longitudinal gap of abutment, transverse gap of shear key, gap inside hinge, length of restrainer, restrainer initial slack, mass, damping 


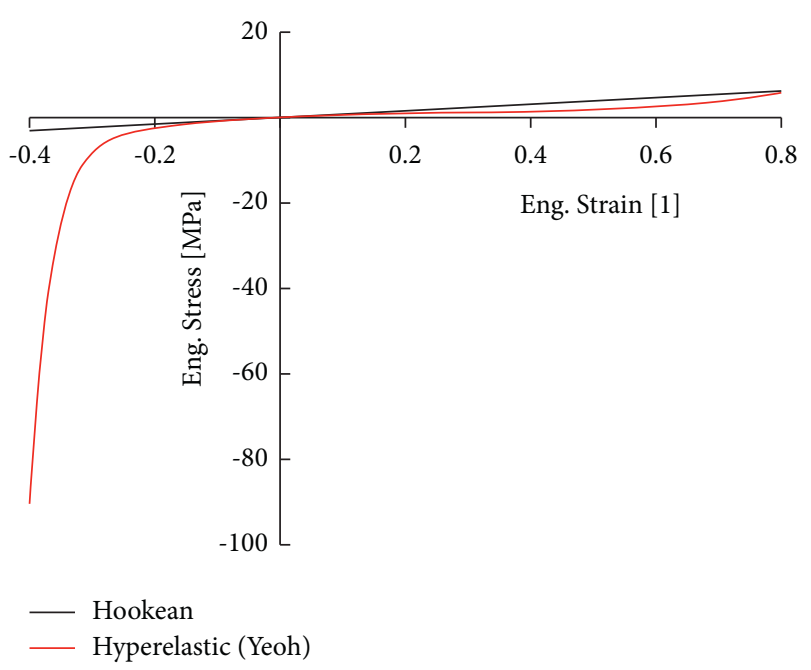

FIGURE 5: Experimental compression curve for elastomeric bearing.

coefficient, were proposed by the work of Ramanathan [37] and Yang et al. [41], as shown in Table 4.

In Table $4, \mu$ and $\sigma$ are mean value and dispersion for normal distribution, and $\lambda$ and $\zeta$ are mean value and dispersion for log-normal distribution, respectively. Meanwhile, up and lo are the upper limit value and lower limit value for uniform distribution, respectively.

\section{Methodology}

3.1. Probabilistic Seismic Demand Model. In order to estimate the damage to structure during earthquake, fragility analysis has been investigated to represent the probability that the seismic response $(D)$ of an engineering demand parameter (EDP) reaches or exceeds a certain limit state $\left(L_{S}\right)$ under the ground motion with a given intensity index (IM). The demand and capacity both follow a logarithmic normal distribution [37, 41], and a peak ground acceleration (PGA) was selected to be the IM of ground motions [41-43]. Single component fragility can be acquired as follows:

$$
P\left[D_{\mathrm{EDP}}>L_{s} \mid \mathrm{IM}\right]=\Phi\left[\frac{\ln S_{D}-\ln S_{L s}}{\sqrt{\beta_{D \mid \mathrm{IM}}^{2}+\beta_{L s}^{2}}}\right],
$$

where $D_{\mathrm{EDP}}$ and $L_{S}$ represent the demand and capacity, $S_{D}$ and $\beta_{D \mid I M}$ represent the median value and the logarithmic standard deviation of demand, $S_{L s}$ and $\beta_{L S}$ represent the median value and the logarithmic standard deviation of capacity, and $\Phi[*]$ represents the standard normal cumulative distribution function.

The relationship between IM and $S_{D}$ can be formulated based on the following:

$$
S_{D}=a(\mathrm{IM})^{b},
$$

where $a$ and $b$ are the regression coefficients, determined by a linear regression from a series of $D_{i}$ and $\mathrm{IM}_{i}$ corresponding to each time-history analysis of the bridge model and $D_{i}$ represents the mean value of peak response of an EDP among the same component of structure under a seismic load. The logarithmic standard deviation of demand can be formulated based on the following:

$$
\beta_{D \mid \mathrm{IM}} \cong \sqrt{\frac{\sum_{i=1}^{N}\left[\ln \left(D_{i}\right)-\ln \left(a \mathrm{IM}_{i}^{b}\right)\right]^{2}}{N-2}} .
$$

Therefore, the fragility of every bridge component can be expressed by the probability distribution of demand, which is a function related to IM [11], called the probabilistic seismic demand model (PSDM). In previous studies [44, 45], the fragility curves of single component such as curvature of column and displacement of girder were often used to represent the fragility of the entire bridge system, which could underestimate the fragility of bridge system $[46,47]$ through replacing the system with a single component. In order to take into account the influence of each component accurately during the seismic evaluation, the joint probability distribution function of seismic demand for the components should be established. In this study, more consideration was given to the correlation between component failure states, so Monte Carlo sampling method $[48,49]$, due to the strong ability to deal with nonlinear problems and high estimation accuracy [50,51], was used to develop the fragility of bridge system.

3.2. Components' Selection. The fragility of bridge components affects not only the evaluation for local damage state of the bridge, but also the evaluation for overall damage state of the bridge. Therefore, bridge components need to be investigated elaborately. In this study, column, abutment passive performance, abutment transverse response, abutment bearing, abutment shear key, hinge restrainer, and plug-type concrete structure in hinge were selected to be assessable components.

The influence of column on the stability and the load capacity of the bridge is prominent, so the curvature ductility was unquestionably classified as the primary component. Longitudinal deformation of bearing at abutment is severely related to the unseating of the bridge, so abutment bearing was categorized as the primary component, accompanied by setting unseating size as the complete limit state median value. Hinge restrainer, a key component that drives the two adjacent frames vibrating collectively, which greatly influences the overall vibration characteristics and the seismic damage state of the bridge, can be categorized as the primary component. The plug-type concrete structure of hinge, a position that is often overlooked and rarely investigated in detail, is subjected to a large vertical supporting reaction in the static state [36]. When an earthquake occurs, the large curvature in $z$ direction in this position, produced by bending moment resulting from the supporting reaction, is liable to give rise to bending failure. In the ultimate limit state, the bending fracture is likely to occur in this position, which can result in unseating in hinge. In consideration of the importance of this position, the curvature ductility in $z$ direction of elements 2 and 3 of the hinge model, shown in Figure 6, was set to be the primary component, called HmcZ for short. Under seismic load, the character of deviation to 

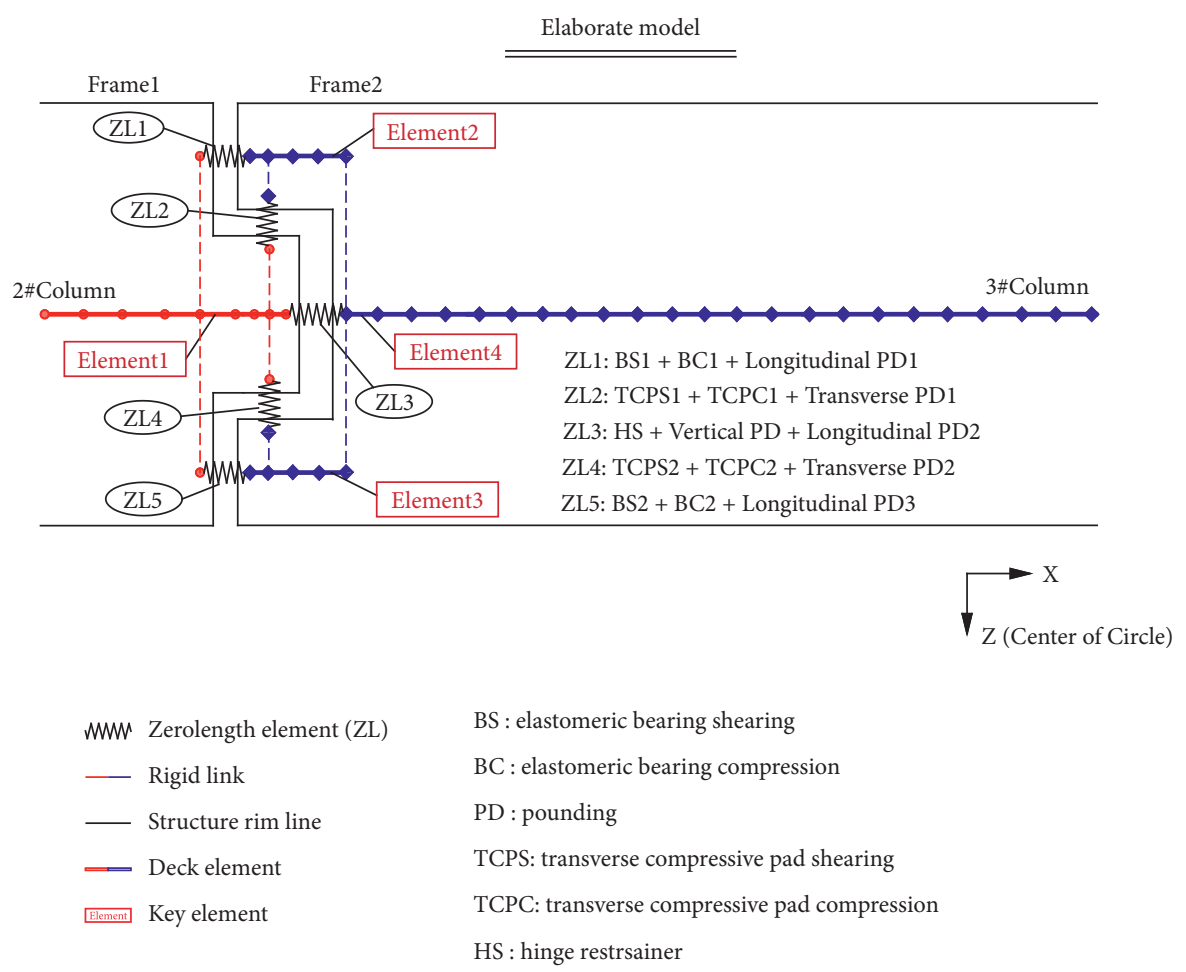

Figure 6: Numerical model of $3 \#$ span with an intermediate hinge.

TABLE 4: Distributions and random variables in bridge modeling.

\begin{tabular}{|c|c|c|c|}
\hline \multirow{2}{*}{ Modeling parameters } & \multirow{2}{*}{ Probability distributions } & \multicolumn{2}{|c|}{ Distribution parameters } \\
\hline & & 1 & 2 \\
\hline Unconfined concrete strength (MPa) & Normal & $\mu=22.10$ & $\sigma=4.26$ \\
\hline Steel yield strength $(\mathrm{MPa})$ & Log-normal & $\lambda=6.13$ & $\zeta=0.08$ \\
\hline Shear modulus of bearing (MPa) & Uniform & lo $=0.94$ & up $=1.36$ \\
\hline Gap (abutment) (mm) & Uniform & lo $=0.00$ & up $=50.80$ \\
\hline Gap (shear key) (mm) & Uniform & lo $=0.00$ & $\mathrm{up}=25.40$ \\
\hline Gap (hinge) $(\mathrm{mm})$ & Uniform & $\mathrm{lo}=50.80$ & up $=101.60$ \\
\hline Length of restrainer (mm) & Uniform & lo $=3556$ & up $=4064$ \\
\hline Initial slack of restrainer (mm) & Uniform & lo $=6.35$ & $\mathrm{up}=25.40$ \\
\hline Mass & Uniform & lo $=0.9$ & up $=1.1$ \\
\hline Damp coefficient & Normal & $\mu=0.045$ & $\sigma=0.0125$ \\
\hline
\end{tabular}

the outer edge of the curve makes the hinge have an evident lateral bending tendency in the position of plug-type concrete structure that may cause the hinge unseating. To sum up, curvature ductility in $y$ direction of elements 2 and 3 of the hinge model, shown in Figure 6, was also set to be the primary component, called $\mathrm{HmcY}$ for short.

During nonlinear failure, on account of the minor influence on bridge system, other components, including abutment passive performance, abutment transverse response, and abutment shear keys, were classified as the secondary component.

3.3. Limit State Capacities. The experimental results and criterion data were identified and selected repeatedly and scrupulously in order to determine the damage descriptions and the damage indexes of bridge components in the limit states at all levels. The limit states were set as four levels, including slight, moderate, extensive, and complete damage, according to Abbasi and Moustafa [11], Ramanathan [37], and Yang et al. [41]. In this study, the primary components contributed to all four limit states $[52,53]$ when performing the fragility analysis of bridge system, while the secondary components contributed only to the slight and moderate limit states. Nevertheless, the secondary components, the same as the primary components, contributed to all four limit states when performing the fragility analysis of components. The limit states of the components are assumed to follow a log-normal distribution. The median value of the distribution has a great influence on the accuracy of fragility analysis. The defined process of the median values for damage indexes of eight components is as follows.

The proposed values from previous studies were often used to represent the median values of limit states for 
column in order to simplify the fragility analysis. Although the data tended to be reasonable within a certain range, the diversity in the form of reinforcement, the size of steel bar, and the size of cross section for columns led to the difference in median values of the limit states for different columns. Therefore, this study performed moment-curvature analysis for seven columns, and the analysis results were regarded as median value of limit states for columns. According to the research of Zhang [54], the damage states of four limit states of columns can be quantified as follows: longitudinal reinforcement yields, concrete compressive strain reaching 0.005 , concrete compressive strain reaching 0.011 and the curvature reaching $0.8 \mu_{\max }$ (ultimate curvature). Momentcurvature analysis [55] of column \#1 to column \#7 was performed, using Xtract, to acquire the effective yield curvature and ultimate curvature, shown as Table 5. During analysis, axial load is equal to the dead load of the bridge assigned to every column. Moment-curvature analysis for columns is illustrated in Figure 7. According to the definition of curvature ductility, $\mu$ is the quotient of actual curvature divided by corresponding effective yield curvature during moment-curvature analysis. Table 6 lists the quantified value $\mu$ of each limit state from column \#1, column \#3, column \#5, and column \#7, which corresponds to the result of Ramanathan [37] for post-1990 ductile column. Therefore, the mean values of $\mu$ from column \#1 to column \#7 are used as the proposed median values eventually.

For the component of abutment passive performance, $19.5 \mathrm{~mm}$ is the proposed median value of slight state, which corresponded to the placement of $1 / 2$ ultimate force of Shamsabadi's model $[30,31]$, shown in Figure 3(g). Referring to the specification of Hazus ${ }^{\circledR} \mathrm{MH} 4$ Technical Manual [56], $50.8 \mathrm{~mm}$ is used to represent the median value of moderate state, summarized from the following provision: "moderate damage of the abutment is defined by moderate movement $(<2)$ ". $76.2 \mathrm{~mm}$ corresponds to the median value of extensive state, which was used to represent CDT- 0 by Ramanathan [37]. The median value, $228.6 \mathrm{~mm}$, of complete state is obtained from displacement of $y_{\max }$ that came from Shamsabadi's model $[30,31]$.

The median value of slight, moderate, and extensive states for the component of abutment footing transverse response, referred from Gadre and Dobry's model [33], shown in Figure $3(\mathrm{~h})$, is $7.6 \mathrm{~mm}, 25.4 \mathrm{~mm}, 50.8 \mathrm{~mm}$ respectively. $101.6 \mathrm{~mm}$, which came from Ramanathan [37] proposed value for CDT-1, is used to represent the median value of complete state.

According to the study by Ramanathan [37], the bearing pads remain elastic until about $100 \%$ shear strain and experience significant damage and tearing over 300 to $350 \%$ shear strain. According to the thickness of abutment bearings, $51.0 \mathrm{~mm}$, the median values of bearings for the slight and extensive states are proposed to be $51.0 \mathrm{~mm}$ and $153.0 \mathrm{~mm}$. Based on the provision of "the maximum shear strain resisted by elastomeric pads prior to failure is estimated at $\pm \% 150$ " from "Caltrans Seismic Design Criteria Version 1.6" [57], $76.5 \mathrm{~mm}$ is used to represent the median value of moderate state. The size of unseating in abutment, $914.4 \mathrm{~m}$, is used to represent the median value of the complete state.
The proposed median values of shear keys for four limit states are calculated from Megally's model [34], shown as Figure 3(i). The calculation is as follows: $\left(D_{y}+\mathrm{Gap}\right) /$ $2=17.2 \mathrm{~mm}$, which is for median value of slight state; $D_{y}=21.6 \mathrm{~mm}$, which is for median value of moderate state; $\left(D_{\max }+D_{y}\right) / 2=542.3 \mathrm{~mm}$, which is for median value of extensive state; $D_{\max }=1063.0 \mathrm{~mm}$, which is for median value of complete state.

The median values of hinge restrainers are as follows: according to the study by Ramanathan [37], "the CDT-0 and CDT- 1 values are set at $75 \%$ and $200 \%$ of the yield displacement," and therefore, the median values of the slight and extensive state are proposed to be $27.3 \mathrm{~mm}$ and $46.4 \mathrm{~mm}$. The median value of moderate state is equal to the yield displacement of restrainers, $31.1 \mathrm{~mm}$. The ultimate deformation of restrainers, $358.8 \mathrm{~mm}$, which corresponds to the ultimate tensile strain of 0.09 , is used to represent the median value of the complete state. The proposed median values include the slack of restrainers.

Similar to the columns, Xtract was used to implement moment-curvature analysis for hinges 1 and 2; the effective yield curvature and the ultimate curvature are obtained, shown in Table 7. Axial load is equal to the longitudinal axial force of the bridge. Moment-curvature analysis for hinge elements is illustrated in Figure 8. Through moment-curvature analysis, concrete compressive strain at the root of occlusion concrete in hinge (elements 2 and 3 ) cannot reach 0.011 , so the damage states of four limit states of the hinges can be quantified as follows: cracking, longitudinal reinforcement yields, concrete compressive strain reaching 0.005 , and the curvature reaching $0.8 \mu_{\max }$ (ultimate curvature). Curvature ductility of hinge is defined as the quotient of actual curvature divided by effective yield curvature, which was transplanted from column. Table 8 lists HmcZ and $\mathrm{HmcY}$ from the moment-curvature analysis and the corresponding damage description. Moreover, the proposed median values of curvature ductility for every limit state were extracted referring to analysis result.

Followed from Ramanathan [37] and Abbasi and Moustafa [11], 0.35 was adopted to represent the dispersion values of log-normal distribution for every component in four limit states, which was proved to be the good estimated value. The proposed median values (med) and dispersion values (disp) of bridge components are listed in Table 9.

\section{Seismic Fragility Assessment}

4.1. Ground Motions. A bin of 48 ground motions, collected from the Rix and Fernandez [58], was used to perform the nonlinear time-history analysis to the typical bridge model. Through each model paired with a set of parameters from Latin hypercube sample, shown as Table 4, 48 groups of typical bridge models, with different material, stiffness, geometry, damp, and mass parameters, were formed to match with 48 ground motions. Therefore, a set of 48 time-history analyses was performed in the typical bridge model to acquire the peak demand of every component. 
TABLE 5: Moment-curvature analysis qualitative description of columns.

\begin{tabular}{|c|c|c|c|c|c|c|c|}
\hline Columns & $\# 1$ & $\# 2$ & $\# 3$ & $\# 4$ & $\# 5$ & $\# 6$ & $\# 7$ \\
\hline Axial load $(\mathrm{kN})$ & 16424 & 21472 & 25059 & 25255 & 27839 & 22209 & 15607 \\
\hline Effective yield curvature $\left(10^{-6} 1 / \mathrm{mm}\right)$ & 1.44 & 1.46 & 1.48 & 1.48 & 1.55 & 1.47 & 1.43 \\
\hline Ultimate curvature $\left(10^{-6} 1 / \mathrm{mm}\right)$ & 29.04 & 27.24 & 25.66 & 25.60 & 23.34 & 26.95 & 29.65 \\
\hline
\end{tabular}
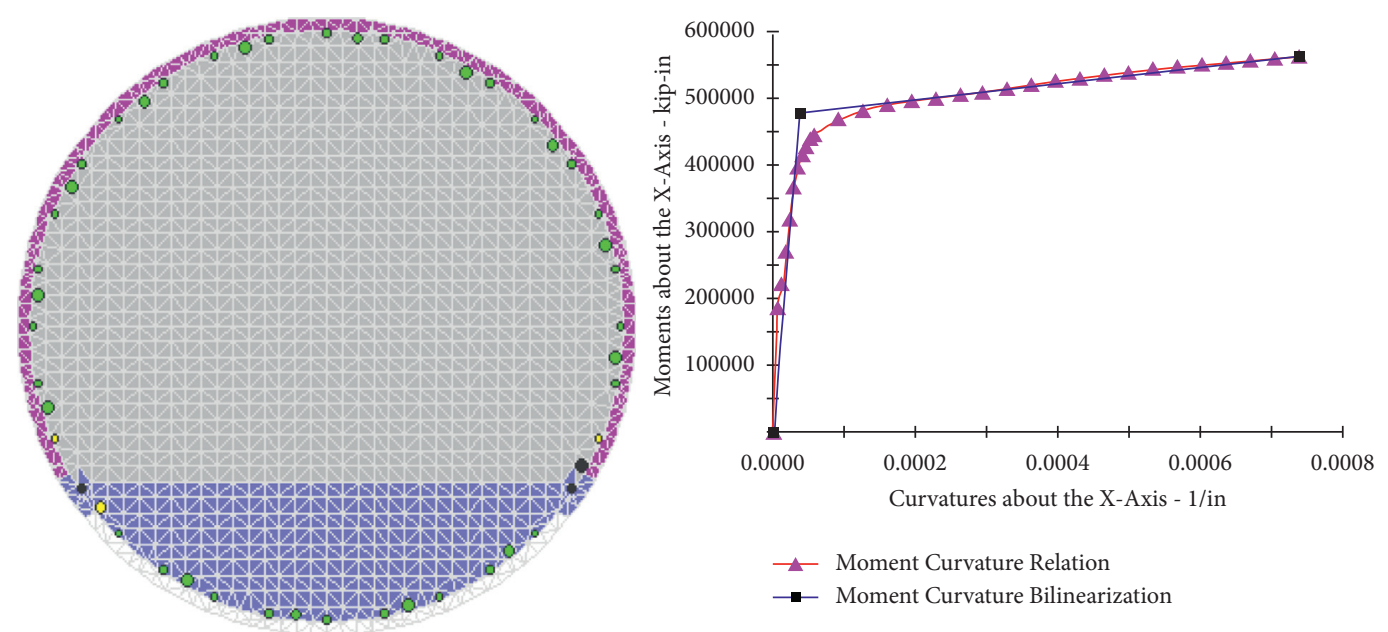

FIgURE 7: Schematic diagram of moment-curvature analysis for columns.

TABLe 6: Curvature ductility of columns for each limit state.

\begin{tabular}{|c|c|c|c|c|c|c|c|}
\hline \multirow[b]{2}{*}{$\begin{array}{l}\text { Limit } \\
\text { state }\end{array}$} & \multirow[b]{2}{*}{ Description } & \multicolumn{4}{|c|}{ Calculated values } & \multirow[b]{2}{*}{$\begin{array}{c}\text { Ramanathan's proposed } \\
\text { values }\end{array}$} & \multirow[b]{2}{*}{$\begin{array}{l}\text { Proposed } \\
\text { values }\end{array}$} \\
\hline & & $\begin{array}{c}\text { Column } \\
\# 1\end{array}$ & $\begin{array}{c}\text { Column } \\
\# 1\end{array}$ & $\begin{array}{l}\text { Column } \\
\# 5\end{array}$ & $\begin{array}{l}\text { Column } \\
\quad \# 7\end{array}$ & & \\
\hline Slight & $\begin{array}{l}\text { Longitudinal reinforcement } \\
\text { yields }\end{array}$ & 0.9 & 1.0 & 0.8 & 0.9 & 1.0 & 0.9 \\
\hline Moderate & $\begin{array}{c}\text { Concrete compressive strain } \\
\text { reaches } 0.005\end{array}$ & $4.3 \sim 5.2$ & $3.2-3.9$ & $2.9 \sim 3.6$ & 4.4 & 4.0 & 4.0 \\
\hline Extensive & $\begin{array}{c}\text { Concrete compressive strain } \\
\text { reaches } 0.011\end{array}$ & $10.8 \sim 11.8$ & $9.5 \sim 10.2$ & 8.3 & 11.1 & 8.0 & 9.0 \\
\hline Complete & Curvature reaches $0.8 \mu_{\max }$ & 16.0 & 13.9 & 12.1 & 16.5 & 12.0 & 14.0 \\
\hline
\end{tabular}

TABle 7: Moment-curvature analysis qualitative description of hinges.

\begin{tabular}{lcc}
\hline Hinges 1,2 & $\mathrm{My}$ & $\mathrm{Mz}$ \\
\hline Axial load $(\mathrm{kN})$ & 1598 & 1598 \\
Effective yield curvature $\left(10^{-6} 1 / \mathrm{mm}\right)$ & 1.66 & 2.20 \\
Ultimate curvature $\left(10^{-6} 1 / \mathrm{mm}\right)$ & 50.79 & 66.34 \\
\hline
\end{tabular}

4.2. Seismic Fragility Parameters. The fragility curves in each limit state are mainly determined by two parameters, median value $\left(\lambda_{f}\right)$, and dispersion value $\left(\beta_{f}\right)$ of log-normal distribution. The corresponding parameters for bridge system and components are listed in Table 10.

The difference of fragility curves for the system and components can be intuitively evaluated by the histograms of median IM value in fragility function. The median PGA values of bridge system and each component are shown in Figure 9. As illustrated in Figure 9, the bridge system has the lowest median PGA value, compared with any other components, across the four limit states, which indicates that the system is more vulnerable than any other components that are consistent with the research results of previous studies $[11,37,41]$.

As found in Figure 9(a), the median PGA values of Abts and $\mathrm{Hs}$ are low and closest to the median PGA value of bridge system in the slight and moderate limit states, which demonstrates that the probabilities of exceeding slight and moderate limit states to the abutment transverse response and the hinge restrainers are large, while these two components are dominant to bridge system fragility in the previously mentioned two states. The median PGA value of $\mathrm{HmcZ}$ is low and much lower than that of HmcY, which indicates that, in the slight and moderate limit states, curvature ductility in $z$ direction of plug-type concrete structure in hinge exhibits a higher fragility than that in $y$ direction.

With reference to Figure 9(b), column and $\mathrm{Hs}$ have the lowest median PGA values in the extensive limit state, which demonstrates that the components have the greatest probability of exceeding the extensive limit state. Further, the median PGA value of Hs is the closest to that of bridge system, indicating that the hinge restrainers have the most dominant influence on the vulnerability of 

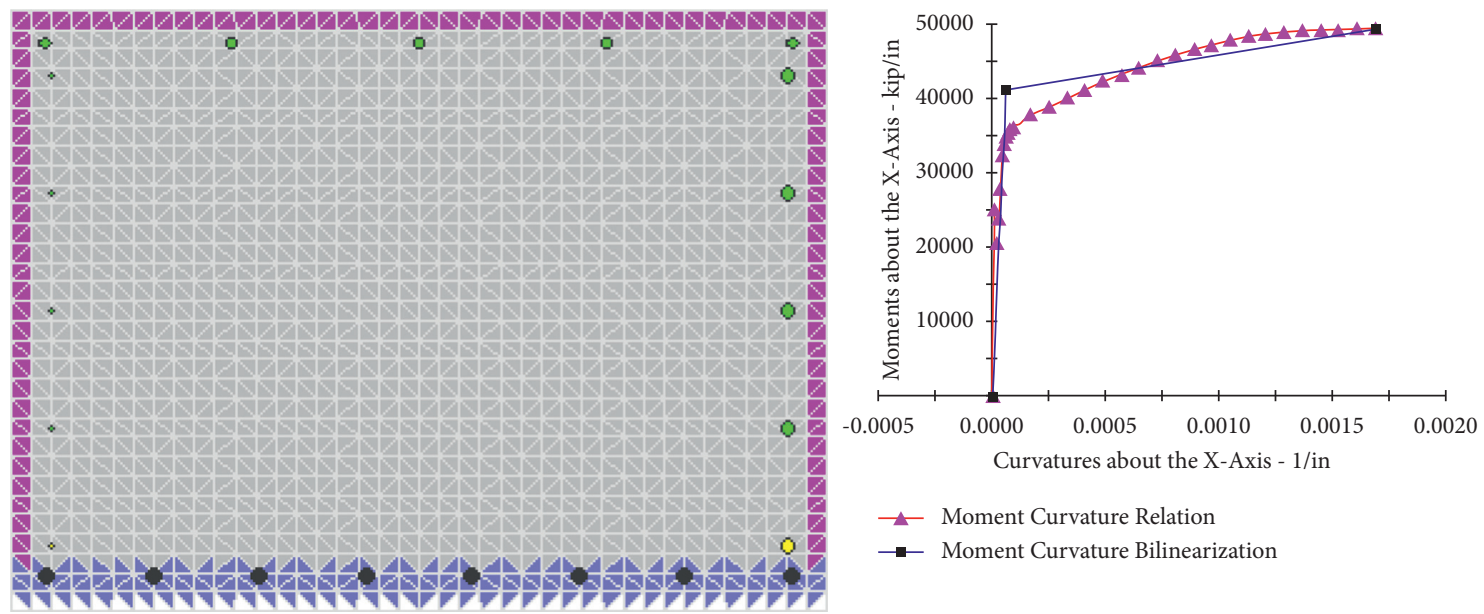

(a)
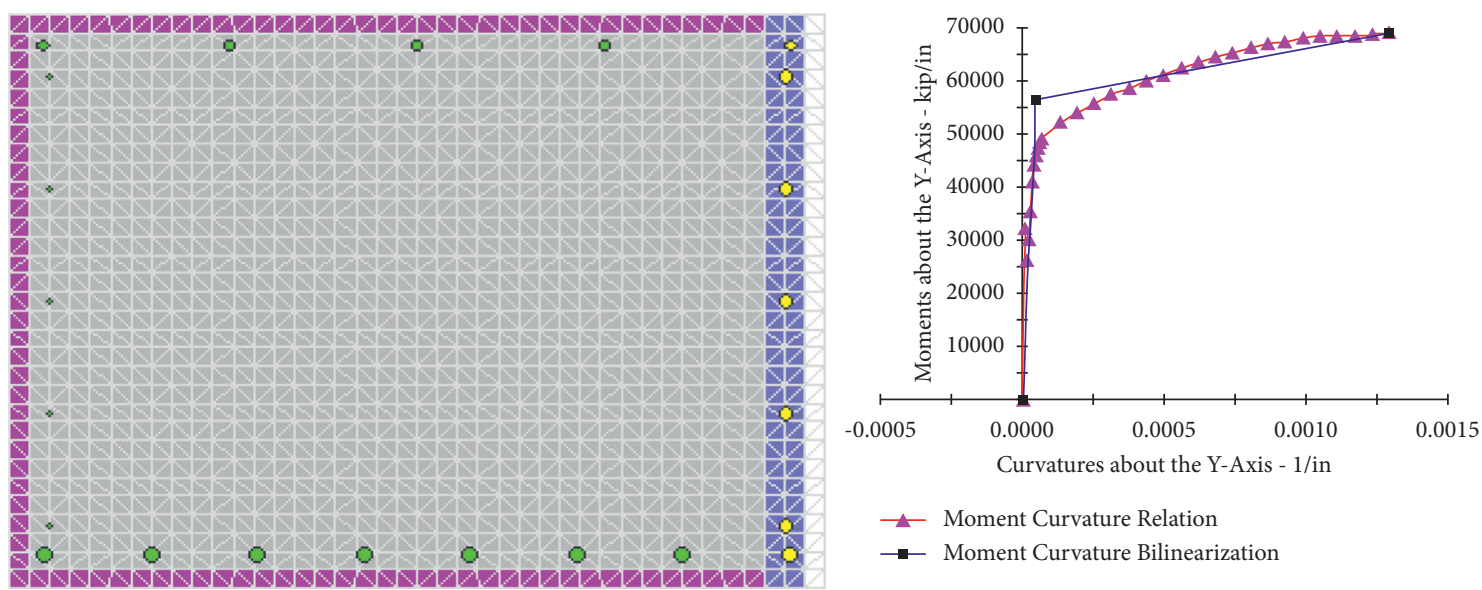

(b)

FIGURE 8: Schematic diagram of moment-curvature analysis for hinges. (a) HmcZ. (b) HmcY.

bridge system in the previously mentioned state. Figure 9(b) also shows that the median PGA value of column, among all primary components, is the lowest in the complete limit state, indicating that the probability of exceeding the complete limit state to column is the largest and column exhibits maximum vulnerability. Based on Figures 9(a) and 9(b), along with the aggravating of the damage state gradually, the median PGA values of column and that of bridge system match gradually and are nearly equal in the complete limit state, which demonstrates that, according to the damage degree aggravation, column is increasingly dominant to bridge system fragility. According to Figure 9(b), in the extensive and complete limit state, both $\mathrm{HmcZ}$ and $\mathrm{HmcY}$ exhibit the high median PGA values, suggesting that the damage probabilities of curvature ductility of plug-type concrete structure in hinge are intensely low. Abb exhibits the intensely large median PGA values in the previously mentioned two states, indicating that the probability of exceeding the extensive state and complete state to abutment bearings is extremely low so that the probability of unseating failure hardly happens at abutment. The large median PGA value of $\mathrm{Hs}$ in the complete limit state signifies the probability of deformation of the hinge restrainers attaining to the ultimate is exceedingly low.

4.3. Seismic Fragility Assessment. The probabilistic seismic demand model of the typical bridge subjected to the suite of synthetic seismic loads was established through performing nonlinear time-history analysis, and the seismic fragility curves of bridge system and components are developed in Figures 10 and 11. The fragility analysis is discussed as follows.

As illustrated in Figure 10(a), column, Hs, and HmcZ exhibit the high probability of exceeding the slight limit state. Although $\mathrm{Abb}$ and $\mathrm{HmcY}$ are not the most vulnerable components, they still have a certain damage exceedance probability in the slight limit state. The fragility curves shown in Figure 10(a), along with the description of the limit states for HmcZ and HmcY discussed in Table 8, demonstrate that the hinge has the risk of the transverse and vertical cracks generating at the root of element next to the supporting point. The risk probability of transverse cracks generating is higher than that of vertical cracks due to the large supporting reaction. 
TABle 8: Curvature ductility of hinges for every limit state.

\begin{tabular}{lccccc}
\hline \multirow{2}{*}{ Limit state } & \multirow{2}{*}{ Description } & \multicolumn{2}{c}{ HmcY } & \multicolumn{2}{c}{ HmcZ } \\
& & Calculated values & Proposed values & Calculated values & Proposed values \\
\hline Slight & Cracking & 0.15 & 0.15 & 0.15 & 0.15 \\
Moderate & Longitudinal reinforcement yields & 1.0 & 1.0 & 0.8 & 1.0 \\
Extensive & Concrete compressive strain reaches 0.005 & $18.9 \sim 23.3$ & 19.0 & $18.7 \sim 23.0$ & 19.0 \\
Complete & Curvature reaches $0.8 \mu_{\max }$ & 24.4 & 24.0 & 24.2 & 24.0 \\
\hline
\end{tabular}

TABLE 9: Limit states of bridge components.

\begin{tabular}{|c|c|c|c|c|c|c|c|c|c|c|c|c|c|c|c|}
\hline & & \multirow{2}{*}{ Components } & \multirow{2}{*}{ Abbreviation } & \multirow{2}{*}{ Units } & \multicolumn{2}{|c|}{ Slight } & \multirow{2}{*}{\multicolumn{2}{|c|}{$\begin{array}{r}\text { Moderate } \\
\text { Med }\end{array}$}} & \multicolumn{2}{|c|}{ Extensive } & \multicolumn{2}{|c|}{ Complete } & \multirow{3}{*}{ Disp } & \multirow{3}{*}{ Med } & \multirow[b]{2}{*}{ Disp } \\
\hline & & & & & & & & & Disp & Med & Disp & Med & & & \\
\hline 1 & Pri & Column & Column & $\mu$ & 0.90 & 0.35 & 4.0 & 0.35 & 9.0 & 0.35 & 14.0 & 0.35 & & & \\
\hline 2 & $\mathrm{Sec}$ & Abutment passive & Abss & $\mathrm{mm}$ & 19.5 & 0.35 & 50.8 & 0.35 & $76.2(1000)$ & 0.35 & $228.6(1000)$ & 0.35 & & & \\
\hline 3 & $\mathrm{Sec}$ & Abutment trans & Abts & $\mathrm{mm}$ & 7.6 & 0.35 & 25.4 & 0.35 & $50.8(1000)$ & 0.35 & $101.6(1000)$ & 0.35 & & & \\
\hline 4 & Pri & Abutment bearing & $\mathrm{Abb}$ & $\mathrm{mm}$ & 51.0 & 0.35 & 76.5 & 0.35 & 153.0 & 0.35 & 914.4 & 0.35 & & & \\
\hline 5 & $\mathrm{Sec}$ & Abutment shear key & Absk & $\mathrm{mm}$ & 17.2 & 0.35 & 21.6 & 0.35 & $542.3(1000)$ & 0.35 & 1063.0 & 0.35 & & & \\
\hline 6 & Pri & Hinge restrainer & $\mathrm{Hs}$ & $\mathrm{mm}$ & 27.3 & 0.35 & 31.1 & 0.35 & 46.4 & 0.35 & 358.8 & 0.35 & & & \\
\hline 7 & Pri & Hinge My (Ele2, 3) & $\mathrm{HmcY}$ & $\mu$ & 0.15 & 0.35 & 1.0 & 0.35 & 19.0 & 0.35 & 24.0 & 0.35 & & & \\
\hline 8 & Pri & Hinge Mz (Ele2, 3) & HmcZ & $\mu$ & 0.15 & 0.35 & 1.0 & 0.35 & 19.0 & 0.35 & 24.0 & 0.35 & & & \\
\hline
\end{tabular}

${ }^{1}$ The values in ( ) are used for fragility analysis of bridge components.

${ }^{2}$ The values outside ( ) are used for fragility analysis of bridge system.

TABLE 10: Fragility parameters for bridge system and components.

\begin{tabular}{|c|c|c|c|c|c|c|c|c|}
\hline \multirow{2}{*}{ System and components } & \multicolumn{2}{|c|}{ Slight } & \multicolumn{2}{|c|}{ Moderate } & \multicolumn{2}{|c|}{ Extensive } & \multicolumn{2}{|c|}{ Complete } \\
\hline & $\lambda_{f}(g)$ & $\beta_{f}$ & $\lambda_{f}(g)$ & $\beta_{f}$ & $\lambda_{f}(g)$ & $\beta_{f}$ & $\lambda_{f}(g)$ & $\beta_{f}$ \\
\hline System & 0.022 & 0.418 & 0.059 & 0.524 & 0.246 & 0.878 & 1.128 & 0.395 \\
\hline Column & 0.180 & 0.399 & 0.504 & 0.399 & 0.882 & 0.399 & 1.197 & 0.399 \\
\hline Abss & 0.219 & 0.971 & 0.490 & 0.971 & - & - & - & - \\
\hline Abts & 0.023 & 0.458 & 0.065 & 0.458 & - & - & - & - \\
\hline Abb & 0.377 & 1.490 & 1.726 & 1.490 & 23.26 & 1.490 & Huge & 1.490 \\
\hline Absk & 1.297 & 2.075 & 2.350 & 2.075 & - & - & - & - \\
\hline $\mathrm{Hs}$ & 0.097 & 1.040 & 0.122 & 1.040 & 0.240 & 1.040 & 7.956 & 1.040 \\
\hline $\mathrm{HmcY}$ & 0.846 & 0.755 & 4.191 & 0.755 & 50.21 & 0.755 & 61.143 & 0.755 \\
\hline $\mathrm{HmcZ}$ & 0.130 & 0.624 & 0.634 & 0.624 & 7.407 & 0.624 & 9.002 & 0.624 \\
\hline
\end{tabular}

Based on Figure 10(b), in the moderate limit state, column and Hs are the most vulnerable components, while $\mathrm{Abb}$ and $\mathrm{HmcZ}$ have certain vulnerability in contrast to the low vulnerability of $\mathrm{HmcY}$. The previously mentioned results indicate that, under seismic load, the deformation of abutment bearings has a risk of exceeding 1.5 times thickness and the hinge has a risk of longitudinal steels yielding at the root of element next to the supporting point. The risk probability of longitudinal steels yielding is greater at the bottom of section than that at its side in hinge.

As shown in Figure 10(c), in the extensive limit state, column and Hs are still the most vulnerable components. Abb, $\mathrm{HmcZ}$, and $\mathrm{HmcY}$ are less vulnerable and have a low probability of exceeding the limit state. The results demonstrate that the deformation of abutment bearings has a low risk of exceeding 3.0 times thickness, and hinges exhibit a low risk of reaching states like shearing cracks, concrete spalling, and section cracks expanding.

According to Figure 10(d), in the complete limit state, the fragility of column, which is high, is close to that of bridge system. Nevertheless, the vulnerabilities of other primary components are low, indicating that the damage of Abb, Hs, HmcY, and HmcZ could hardly exceed the complete limit state. The discussion demonstrates that the probability of the unseating failure at abutment and hinge is extremely low and the fracture failure at the intermediate hinge can hardly be generated.

Figures 11(a) and 11(b) illustrate that the fragility curves of bridge system and the fragility curves of Abts overlap fundamentally in the slight and moderate limit states, which indicates that Abts has the most prominent influence on the fragility of bridge system in these two limit states.

According to Figures 11(c) and 11(d), in the extensive and complete limit states, the fragility of Absk is basically zero, which demonstrates the probabilities that shear keys exceed the extensive and complete limit states are very little. Shear keys with lateral large stiffness transfer the inertial force from superstructure to abutment smoothly, which cannot generate the relative lateral misplaced failure between abutment and superstructure. Nevertheless, the inertial force from superstructure will be transmitted to the abutment foundation through the 

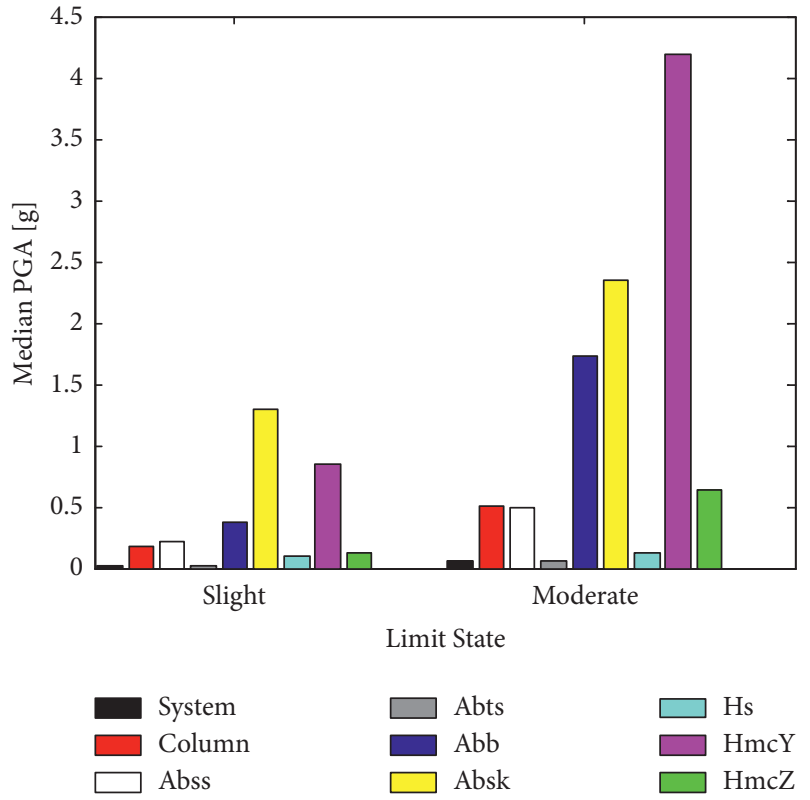

(a)

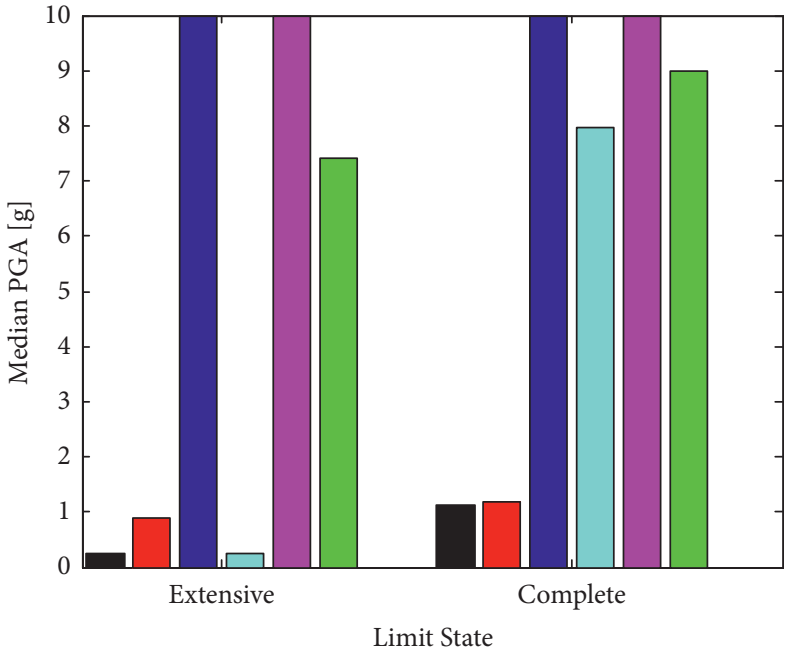

System
Column
Abb

$\square \mathrm{Hs}$

$\square \mathrm{HmcY}$

$\square \mathrm{HmcZ}$

(b)

FIgure 9: Median PGA values of calculated fragility functions for bridge system and all components in the (a) slight and moderate limit states and (b) extensive and complete limit states.

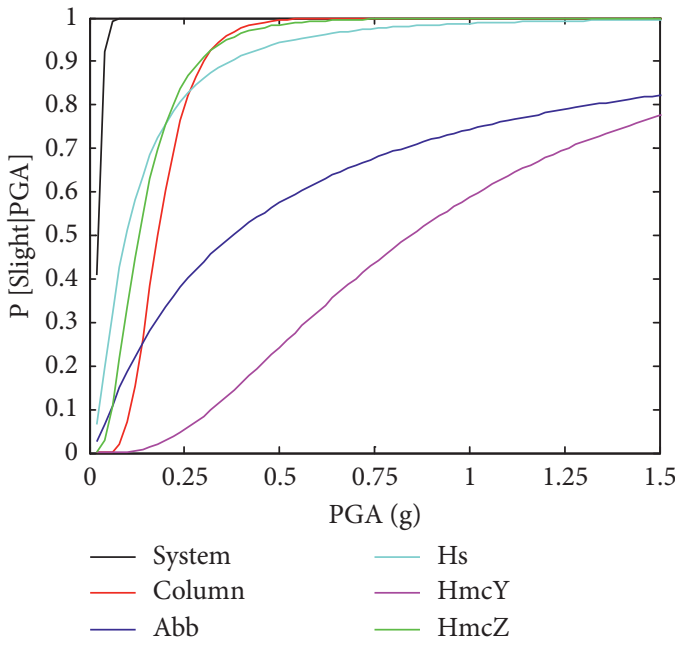

(a)

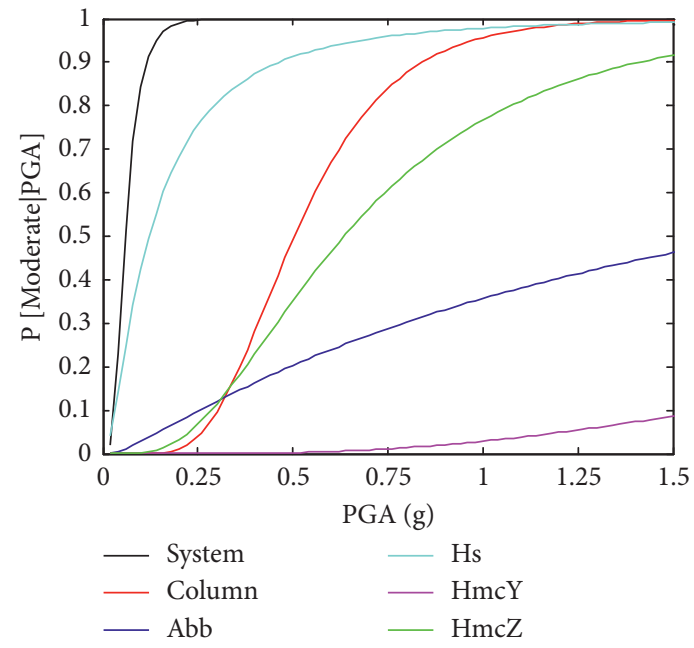

(b)

FIgURE 10: Continued. 


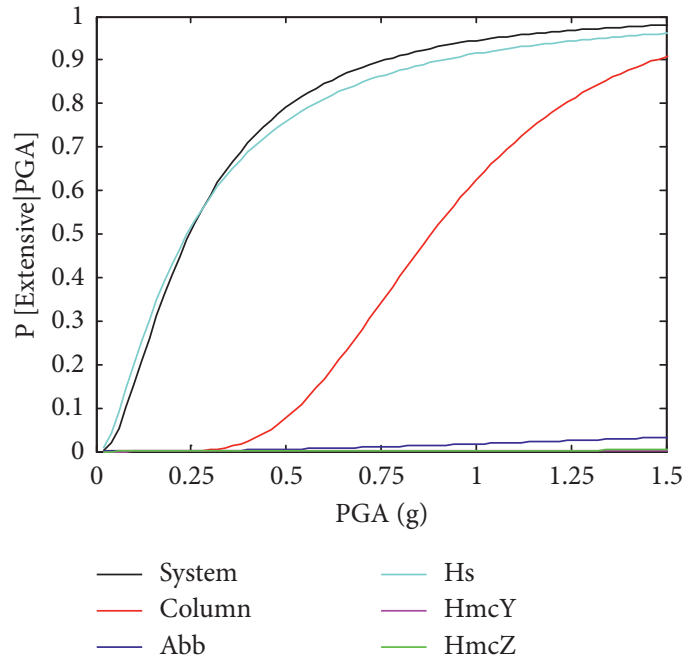

(c)

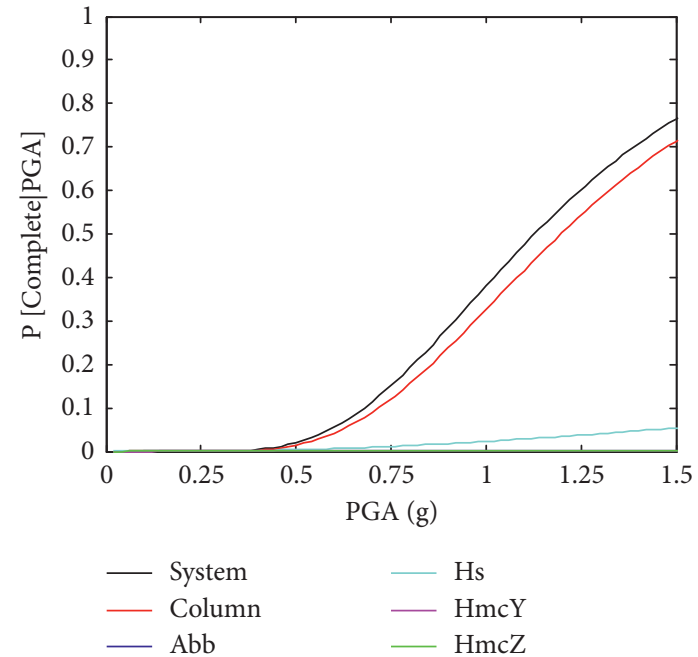

(d)

FIGURE 10: Seismic fragility curves of the system and primary components in the (a) slight, (b) moderate, (c) extensive, and (d) complete limit states.
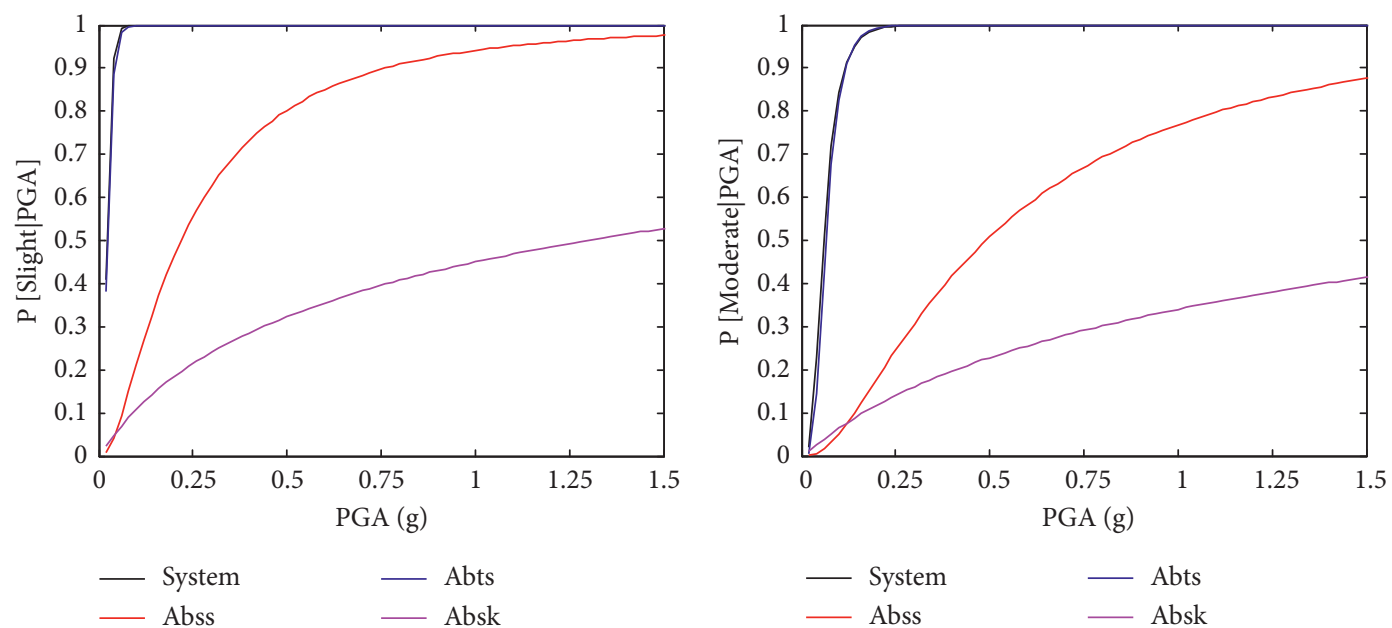

(a)

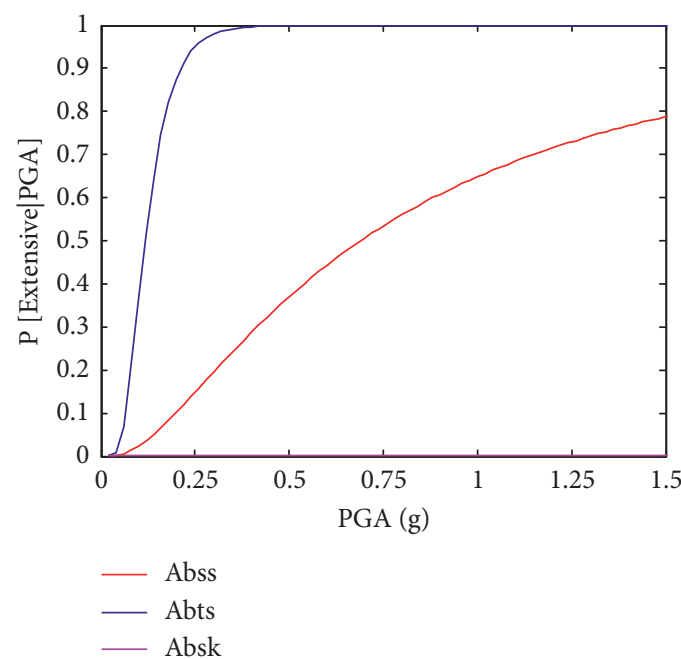

(b)

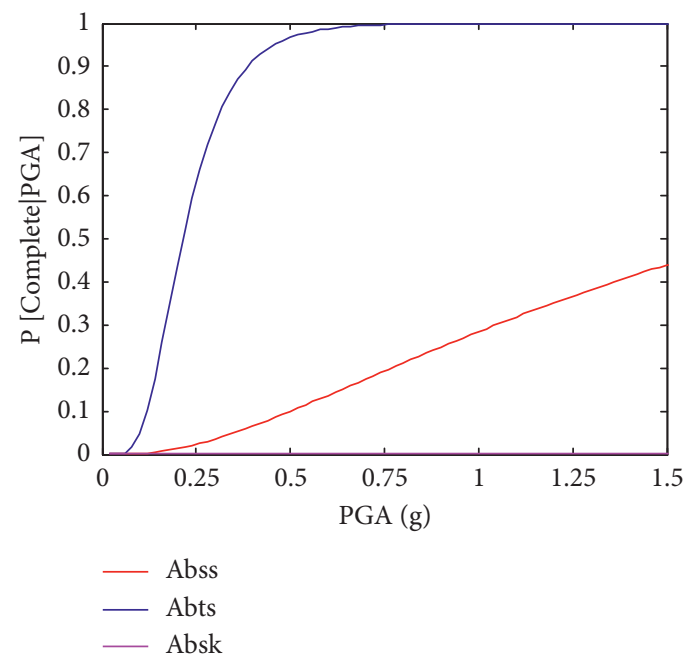

(c)

(d)

FIGURE 11: Seismic fragility curves of the system and secondary components in the (a) slight, (b) moderate, (c) extensive, and (d) complete limit states. 
shear keys, which could result in the huge damage of abutment transverse response.

\section{Summary and Conclusions}

Fragility assessment of a multiframe prestressed concrete box-girder bridge with intermediate hinges, located in California, was performed in this study. Elaborate modeling along with definition of damage indexes for components could be used as a template to the similar type of bridge. Through fragility analysis of bridge system and components, the following conclusions can be obtained.

Column exhibits high fragility across all four limit states. Moreover, in the complete limit state, column fragility is extremely close to bridge system fragility, which indicates that bridge system fragility is gradually determined by columns along with aggravating of damage state. Abb exhibits certain fragility in the slight and moderate limit states, while the fragility is intensely low, almost zero, in the extensive and complete limit states, which manifests that the deformation of abutment bearings is arduous to exceed 3.0 times thickness, and the probability of unseating occurring at abutment is virtually impossible. Hs has high fragility across the three limit states of slight, moderate, and extensive, while, in the complete limit state, the fragility is intensely low, almost zero, which indicates that the probability of ultimate deformation occurring at intermediate hinge is extremely low. HmcZ has high fragility in the slight limit state, certain fragility in the moderate state, and almost no fragility in the extensive and complete state. HmcY has certain fragility in the slight limit state, low fragility in the moderate state, and almost no fragility in the extensive and complete state.

The fragility results demonstrate that transverse and vertical cracks are generated at intermediate hinges with a high probability during earthquake; meanwhile, the probability of generating transverse cracks is greater than that of generating vertical cracks. Besides, there is a risk of longitudinal steels yielding in these positions, which is greater at the bottom of section than that at its side. It can be speculated that the large reaction force from supporting point could give rise to the large bending moment at the bottom of intermediate hinges, which would raise the risk of fracture failure in these positions. Obviously, seismic damage probability in the plug-type hinge exists deterministically, especially in the slight limit state and moderate limit state, which cannot be ignored. Construction errors, which may result in size deviation of hinges or installation deviation of inhibiting devices in hinges, could greatly affect the fragility of intermediate hinges and even threaten the safety of the whole bridge. Among all errors, the deviation of elastomeric bearings in hinges could lead to the most serious influence on the bridge.

\section{Data Availability}

The data used to support the findings of this study are included within the article.

\section{Conflicts of Interest}

The authors declare that there are no conflicts of interest regarding the publication of this paper.

\section{Acknowledgments}

This research was supported by (i) the Basic Research Expense Project of Heilongjiang Provincial Colleges and Universities (Grant no. 2020-KYYWF-1039) and (ii) the National Natural Science Foundation of China (NSFC) (Grant no. 11774081).

\section{References}

[1] B. A. Castillo, S. F. McGill, K. M. Scharer et al., "Prehistoric earthquakes on the banning strand of the san andreas fault, north palm springs, California," Geosphere, vol. 17, no. 3, pp. 685-710, 2021.

[2] K. Blisniuk, K. Scharer, W. D. Sharp, R. Burgmann, C. Amos, and M. Rymer, "A revised position for the primary strand of the pleistocene-holocene san andreas fault in southern California," Science Advances, vol. 7, no. 13, p. 14, Article ID eaaz5691, 2021.

[3] M. Mehr and A. E. Zaghi, "Modified elastic dynamic analysis (eda) for seismic demand on in-span hinge shear keys in multi-frame bridges," Transportation Research Record: Journal of the Transportation Research Board, vol. 2672, no. 41, pp. 75-86, 2018.

[4] E. Aboutorabian and M. Raissi Dehkordi, "Numerical study of seismic response of irregular multi-frame reinforced concrete bridges," Proceedings of the Institution of Civil Engineers Structures and Buildings, vol. 173, no. 11, pp. 783-798, 2020.

[5] M. A. Hube and K. M. Mosalam, "Experimental and computational evaluation of current and innovative in-span hinge details in reinforced concrete box-girder bridges," Report PEER 2008/103, Pacific Earthquake Engineering Center, PEER, Berkeley, CA, USA, 2008.

[6] J.-S. Jeon, S. Mangalathu, J. Song, and R. Desroches, "Parameterized seismic fragility curves for curved multi-frame concrete box-girder bridges using bayesian parameter estimation," Journal of Earthquake Engineering, vol. 23, no. 6, pp. 954-979, 2019.

[7] M. Mehr and A. E. Zaghi, "Seismic response of multi-frame bridges," Bulletin of Earthquake Engineering, vol. 14, no. 4, pp. 1219-1243, 2016.

[8] J.-S. Jeon, R. DesRoches, T. Kim, and E. Choi, "Geometric parameters affecting seismic fragilities of curved multi-frame concrete box-girder bridges with integral abutments," Engineering Structures, vol. 122, no. 1, pp. 121-143, 2016.

[9] R. DesRoches and G. L. Fenves, "Simplified restrainer design procedure for multiple-frame bridges," Earthquake Spectra, vol. 17, no. 4, pp. 551-567, 2001.

[10] G. L. Fenves and M. Ellery, "Behavior and failure analysis of a multiple-frame highway bridge in the 1994 northridge earthquake," Report PEER 1998/08, Pacific Earthquake Engineering Research Center, PEER), Berkeley, CA, USA, 1998.

[11] M. Abbasi and M. A. Moustafa, "Time-dependent seismic fragilities of older and newly designed multi-frame reinforced concrete box-girder bridges in California," Earthquake Spectra, vol. 35, no. 1, pp. 233-266, 2019.

[12] Y. Youb, A. Kadid, and H. Lombarkia, "Analysis of the postmainshock behavior of reinforced concrete bridge pier 
columns subjected to aftershocks," Jordan Journal of Civil Engineering, vol. 15, no. 2, pp. 193-208, 2021.

[13] M. Sajed and P. Tehrani, "Effects of column and superstructure irregularity on the seismic response of four-span RC bridges," Structure, vol. 28, pp. 1400-1412, 2020.

[14] X. Li, K. D. Chen, P. Hu, W. He, L. Xiao, and R. Zhang, "Effect of ECC jackets for enhancing the lateral cyclic behavior of RC bridge columns," Engineering Structures, vol. 219, Article ID 110714, 2020.

[15] C. Y. Jiao, J. Z. Li, B. Wei, P. Long, and Y. Xu, "Experimental investigations on seismic responses of RC circular column piers in curved bridges," Earthquakes and Structures, vol. 17, no. 5, pp. 435-445, 2019.

[16] S. Kurino, W. Wei, and A. Igarashi, "Seismic fragility and uncertainty mitigation of cable restrainer retrofit for isolated highway bridges incorporated with deteriorated elastomeric bearings," Engineering Structures, vol. 237, Article ID 112190, 2021.

[17] R. Sarkar and K. Pareek, "Influence of stratification and assessment of fragility curves for mountain tunnels," Proceedings of the Institution of Civil Engineers-Geotechnical Engineering, vol. 174, no. 3, pp. 279-290, Article ID 1900134, 2021.

[18] S. Song, S. Wang, G. Wu, and B. S. Xu, "Seismic vulnerability analysis of small and medium span girder bridges," Journal of Vibration and Shock, vol. 39, no. 9, pp. 118-125, 2020.

[19] Z. Zhao, X. W. Lu, Y. Guo, and X. Zhao, "Seismic fragility assessment of base-isolated steel water storage tank," Shock and Vibration, vol. 2020, Article ID 8835943, 13 pages, 2020.

[20] H. Derakhshan, K. Q. Walsh, J. M. Ingham, M. C. Griffith, and D. P. Thambiratnam, "Seismic fragility assessment of nonstructural components in unreinforced clay brick masonry buildings," Earthquake Engineering \& Structural Dynamics, vol. 49, no. 3, pp. 285-300, 2019.

[21] F. McKenna and G. L. Fenves, Open System for Earthquake Simulation Framework (OpenSees) Ver. 2.4.4. Pacific Earthquake Engineering Research Center (PEER), University of California, Berkeley, CA, USA, 2014.

[22] G. A. Chang and J. B. Mander, "Seismic energy based fatigue damage analysis of bridge columns: part I- evaluation of seismic capacity," Technical Report 94-0006, NCEER, Buffalo, NY, USA, 1994.

[23] J. D. Waugh, "Nonlinear analysis of T-shaped concrete walls subjected to multidirectional displacements," Ph.D. Thesis, Iowa State University, Ames, IA, USA, 2009.

[24] D. Lehman, J. Moehle, S. Mahin, A. Calderone, and L. Henry, "Experimental evaluation of the seismic performance of reinforced concrete bridge columns," Journal of Structural Engineering, vol. 130, no. 6, pp. 869-879, 2004.

[25] F. C. Filippou, E. P. Popov, and V. V. Bertero, Effects of Bond Deterioration on Hysteretic Behavior of Reinforced Concrete Joints, Report EERC 83-19, Earthquake Engineering Research Center, University of California, Berkeley, CA, USA, 1983.

[26] S. Muthukumar, A contact element approach with hysteresis damping for the analysis and design of pounding in bridges, Ph.D. Thesis, Georgia Institute of Technology, Atlanta, GA, USA, 2003.

[27] MSC Software Corporation, Nonlinear Finite Element Analysis of Elastomers, MSC Software: Whitepaper Report, Santa Ana, CA, USA, 2000.

[28] R. DesRoches and S. Muthukumar, "Implications of seismic pounding on the longitudinal response of multi-span bridgesan analytical perspective," Earthquake Engineering and Engineering Vibration, vol. 3, no. 1, pp. 57-65, 2004.
[29] B. G. Nielson, Analytical fragility curves for highway bridges in moderate seismic zones, Ph.D. Thesis, Georgia Institute of Technology, Atlanta, GA, USA, 2005.

[30] A. Shamsabadi, K. M. Rollins, and M. Kapuskar, "Nonlinear soil-abutment-bridge structure interaction for seismic performance-based design," Journal of Geotechnical and Geoenvironmental Engineering, vol. 133, no. 6, pp. 707-720, 2007.

[31] A. Shamsabadi and L. Yan, "Closed-form force-displacement backbone curves for bridge abutment-backfill systems," Geotechnical Earthquake Engineering and Soil Dynamics Congress, vol. IV, 2008.

[32] G. Gazetas and J. L. Tassoulas, "Horizontal stiffness of arbitrarily shaped embedded foundations," Journal of Geotechnical Engineering, vol. 113, no. 5, pp. 440-457, 1987.

[33] A. Gadre and R. Dobry, "Lateral cyclic loading centrifuge tests on square embedded footing," Journal of Geotechnical and Geoenvironmental Engineering, vol. 124, no. 11, pp. 11281138, 1998.

[34] S. H. Megally, P. F. Silva, and F. Seible, "Seismic response of sacrificial shear keys in bridge abutments," Structural Systems Research Project, Report No. SSRR-2001/23, University of California, San Diego, CA, USA, 2002.

[35] A. Bozorgzadeh, S. Megally, J. I. Restrepo, and S. A. Ashford, "Capacity evaluation of exterior sacrificial shear keys of bridge abutments," Journal of Bridge Engineering, vol. 11, no. 5, pp. 555-565, 2006.

[36] T. Wu and Q. S. Sun, "Study and analysis for seismic response of hinge in frame-style curved girder bridge," Engineering Mechanics, vol. 33, no. 10, pp. 155-163, 2016, (in Chinese).

[37] K. N. Ramanathan, Next generation seismic fragility curves fro california bridges incorporating the evolution in seismic design philosophy, Ph.D. Thesis, Georgia Institute of Technology, Atlanta, GA, USA, 2012.

[38] W. M. Isenhower, S. T. Wang, and L. G. Vasquez, A Program to Analyze Deep Foundations under Lateral Loading, User's Manual for LPile 2018, 2018.

[39] X. B. Hu, C. Lu, and X. Q. Zhu, "A simplified model for dynamic response analysis of framed self-centering wall structures under seismic excitations," Shock and Vibration, vol. 2019, Article ID 2360150, 14 pages, 2019.

[40] S. Hamidpour and M. Soltani, "Probabilistic assessment of ground motions intensity considering soil properties uncertainty," Soil Dynamics and Earthquake Engineering, vol. 90, pp. 158-168, 2016.

[41] C.-S. W. Yang, S. D. Werner, and R. DesRoches, "Seismic fragility analysis of skewed bridges in the central southeastern United States," Engineering Structures, vol. 83, pp. 116-128, 2015.

[42] F. Che, C. Yin, J. L. Zhou et al., "Embankment seismic fragility assessment under the near-fault pulse-like ground motions by applying the response surface method," Shock and Vibration, vol. 2021, Article ID 8849043, 15 pages, 2021.

[43] Z. P. Song, J. C. Mao, X. X. Tian, Y. Jang, and J. Wang, "Optimization analysis of controlled blasting for passing through houses at close range in super-large section tunnels," Shock and Vibration, vol. 2019, Article ID 1941436, 16 pages, 2019.

[44] A. Kibboua, M. Naili, D. Benouar, and F. Kehila, "Analytical fragility curves for typical Algerian reinforced concrete bridge piers," Structural Engineering \& Mechanics, vol. 39, no. 3, pp. 411-425, 2011.

[45] J. Simon, J. M. Bracci, and P. Gardoni, "Seismic response and fragility of deteriorated reinforced concrete bridges," Journal of Structural Engineering, vol. 136, no. 10, pp. 1273-1281, 2010. 
[46] S. Song, Y. J. Qian, and G. Wu, "Research on seismic fragility method of bridge system based on copula function," Engineering Structures, vol. 33, no. 11, pp. 193-200, 2016.

[47] K. F. Zheng, L. B. Chen, W. L. Zhuang, H.-S. Ma, and J. J. Zhang, "Bridge vulnerability analysis based on probabilistic seismic demand models," Engineering Mechanics, vol. 30, no. 5, pp. 165-171, 2013.

[48] Y. H. Gu, Y. C. Liu, and C. D. Lu, "Brake noise reduction method based on Monte Carlo sampling and particle swarm optimization," Shock and Vibration, vol. 2021, Article ID 8878223, 11 pages, 2021.

[49] X. Q. Chen, Z. P. Shen, and X. Liu, "A copula-based and Monte Carlo sampling approach for structural dyamics model updating with interval uncertainty," Shock and Vibration, vol. 2018, Article ID 3958016, 11 pages, 2018.

[50] B. G. Nielson and R. DesRoches, "Seismic fragility methodology for highway bridges using a component level approach," Earthquake Engineering \& Structural Dynamics, vol. 36, no. 6, pp. 823-839, 2007.

[51] E. Choi, R. DesRoches, and B. Nielson, "Seismic fragility of typical bridges in moderate seismic zones," Engineering Structures, vol. 26, no. 2, pp. 187-199, 2004.

[52] K. K. Moridani, P. Zarfam, and M. G. Ashtiany, "Seismic failure probability of a curved bridge based on analytical and neural network approaches," Shock and Vibration, vol. 2017, Article ID 2408234, 18 pages, 2017.

[53] C. Zhang, C. W. Wu, and P. G. Wang, "Seismic fragility analysis of bridge group pile foundations considering fluidpile-soil Interaction," Shock and Vibration, vol. 2020, Article ID 8838813, 17 pages, 2020.

[54] Y. Zhang, P. Tan, J. X. Zheng, and F. L. Zhou, "Seismic fragility analysis on isolated brdiges with flexible column piers," Journal of Vibration and Shock, vol. 34, no. 16, pp. 48-54, 2015.

[55] H. J. Zhao, Q. N. Li, J. Zhao, S. F. Li, and Y. Zheng, "Calculation method for moment-curvature of high strength concrete shear wall confined with high strength rectangle spiral reinforcements," Engineering Mechanics, vol. 37, no. 9, pp. 123-132, 2020.

[56] Earthquake model technical manual, Department of Homeland Security, Federal Emergency Management Agency, Vol. 4, Hazus-MH MR, Mitigation Division, Washington, D.C, 2003.

[57] Caltrans 1.6, Caltrans Seismic Design Criteria, California Department of Transportation, Sacramento, CA, USA, 2010.

[58] G. J. Rix and J. A. Fernandez, "Synthetic ground motions for memphis," TN http://geosystems. ce.gatech.edu/soil_dynamics/research/groundmotionsembay/, 2004. 